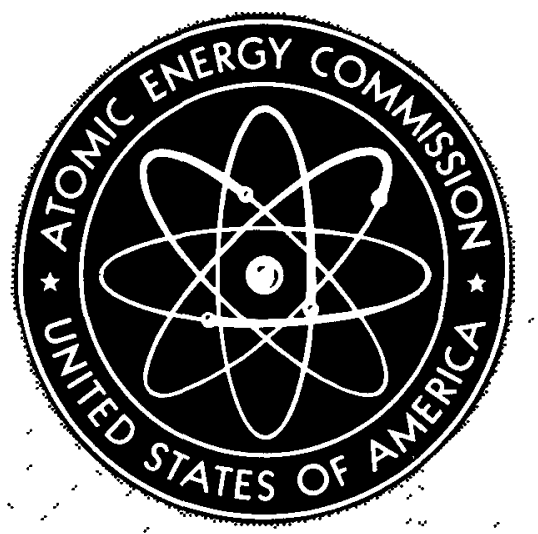

\title{
MASTER
}

GA-3069

\section{ANALYSIS OF ACTIVATION MEASUREMENTS OF Th232 RESONANCE CAPTURES IN THE PEACH BOTTOM (40-MW(E) PROTOTYPE HTGR) CRITICAL ASSEMBLY}

By

J. B. Sampson

September 14, 1962

General Atomic Division

General Dynamics Corporation

San Diego, California 


\section{LEGAL NOTICE}

This report was prepared as an account of Government sponsored work. Neither the United States, nor the Commission, nor any person acting on behalf of the Commission:

A. Makes any warranty or representation, expressed or implied, with respect to the accuracy, completeness, or usefulness of the information contained in this report, or that the use of any information, apparatus, method, or process disclosed in this report may not infringe privately owned rights; or

B. Assumes any liabilities with respect to the use of, or for damages resulting from the use of any information, apparatus, method, or process disclosed in this report.

As used in the above, "person acting on behalf of the Commission" includes any employee or contractor of the Commission, or employee of such contractor, to the extent that such employee or contractor of the Commission, or employee of such contractor prepares, disseminates, or provides access to, any information pursuant to his employment or contract with the Commission, or his employment with such contractor.

This report has been reproduced directly from the best available copy.

Printed in USA. Price $\$ 2.00$. Avallable from the Office of Technical Services, Department of Commerce, Washington 25, D. C. 


\section{DISCLAIMER}

This report was prepared as an account of work sponsored by an agency of the United States Government. Neither the United States Government nor any agency Thereof, nor any of their employees, makes any warranty, express or implied, or assumes any legal liability or responsibility for the accuracy, completeness, or usefulness of any information, apparatus, product, or process disclosed, or represents that its use would not infringe privately owned rights. Reference herein to any specific commercial product, process, or service by trade name, trademark, manufacturer, or otherwise does not necessarily constitute or imply its endorsement, recommendation, or favoring by the United States Government or any agency thereof. The views and opinions of authors expressed herein do not necessarily state or reflect those of the United States Government or any agency thereof. 


\section{DISCLAIMER}

Portions of this document may be illegible in electronic image products. Images are produced from the best available original document. 
DIVISION OF

\section{GENERAL DYNAMICS}

JOHN JAY HOPKINS LABORATORY FOR PURE AND APPLIED SCIENCE

PO BOX 608 SAN DIEGO 12 CALIFORNIA

GA-3069

REACTOR TECHNOLOGY

ANALYSIS OF ACTIVATION MEASUREMENTS OF Th ${ }^{232}$ RESONANCE CAPTURES IN THE PEACH BOTTOM (40-MW(E) PROTOTYPE HTGR) CRITICAL ASSEMBLY

Work done by:

R. G. Bardes

R. K. Lane

J. B. Sampson

L. J. Todt
Report written by:

J. B. Sampson

U.S. Atomic Energy Commission

Contract AT(04-3)-314 


\section{SUMMARY}

Measurements of thorium resonance-capture activations ${ }^{*}$ relative to those of $\mathrm{Au}{ }^{197}$ which were made in the Peach Bottom (HTGR) critical assembly are analyzed and compared with thorium resonance activations calculated from tabulated values of the resonance parameters. The new vanadium-subtraction method that has been applied is shown to measure thorium resonance captures relative to those of $\mathrm{Au}{ }^{197}$ to within several per cent in this geometry. The measurements show that the lowest several resonances of thorium capture less strongly than would be predicted by the listed parameters. This reduced capture is such that the thin-limit, epicadmium $1 / E$-spectrum resonance integral is about $84 \mathrm{~b}$ instead of the $96 \mathrm{~b}$ predicted by listed parameters; the thorium resonance captures for the critical assembly are about $6 \%$ less. The approximations currently used in calculating resonance captures in annular lattices probably underestimate captures by several per cent. The $300^{\circ} \mathrm{K}$ resonance-capture rate of $\mathrm{ThO}_{2}$ in the annulus is indicated to be several per cent larger than that of metallic thorium, presumably because of a solid-state effect.

\footnotetext{
* The technique of measurement is described in Ref. 1 .
} 
○

4 
CONTENTS

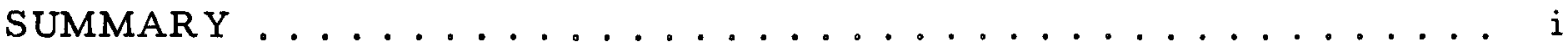

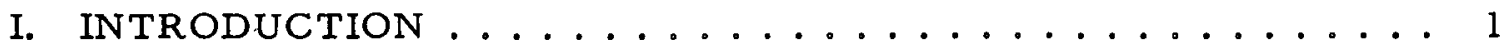

II. METHODS OF MEASUREMENT AND REDUCTION OF

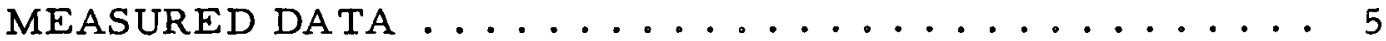

2. 1. The Vanadium-subtraction Technique .......... 5

2. 2. The Cadmium-ratio Technique ............. 12

2. 3. Calculation of Detector-foil Characteristics .......16

2. 4. Absorption Cross Section of Aul97 ........... 17

2. 5. Calculation of Reactor Neutron Spectra and Aul97

Resonance-capture Reaction Rates ........... 21

III. METHOD OF CALCULATION OF Th232 RESONANCE REAC-

TION RATE FROM CROSS-SECTION DATA ........ 31

3. 1. Status of Knowledge of Thorium Absorption Cross

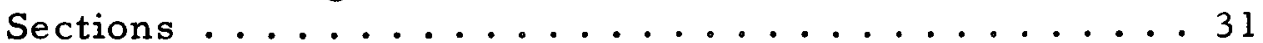

3. 2. Details of Technique of Computation of Thorium Resonance Capture from Thorium Cross-section Data . . . 36

IY. MEASURED RELATIVE ACTIVATIONS AND CADMIUM

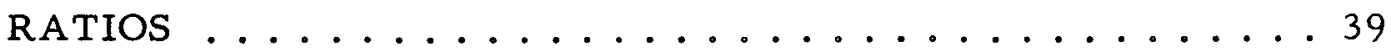

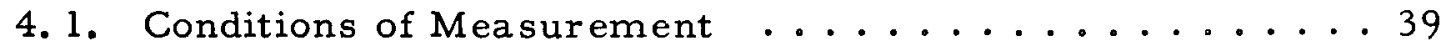

4. 2. Cadmium Ratios Measured in Triflutes .......... 40

4. 3. Activation Ratios Measured by the Vanadium-subtraction

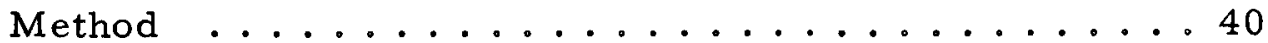

V. CADMIUM-RATIO-MEASURED RESONANCE CAPTURE

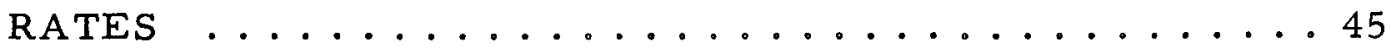

VI. RESULTS OF RESONANCE-CAPTURE MEASUREMENTS BY THE VANADIUM-SUBTRACTION TECHNIQUE ....... . 49

VII. QUANTITATIVE CALCULATION OF THORIUM RESONANCE

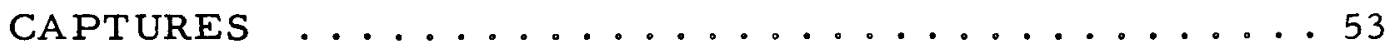

7. 1. Special Correction to Calculated Resonance-capture

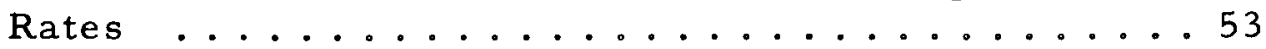

7.2. Computational Corrections to GAM-I Result Determined by Comparison with ZUT .............. 54

7.3. Final Calculated Values of Vanadium-subtractionmeasured Values of the Thorium Resonance-capture

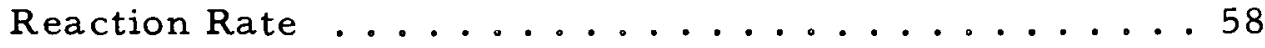


VIII. COMPARISON OF CALCULATED AND MEASURED RESULTS OF THORIUM RESONANCE CAPTURES .......... 61

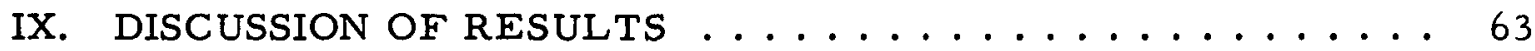

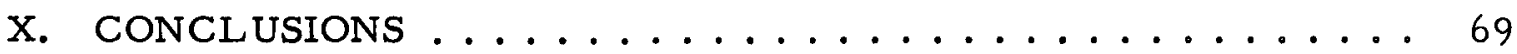

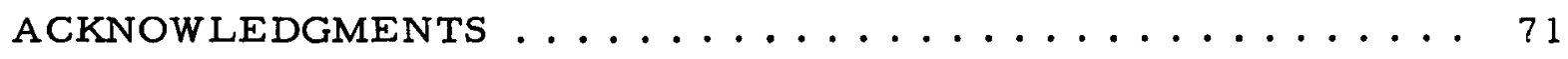

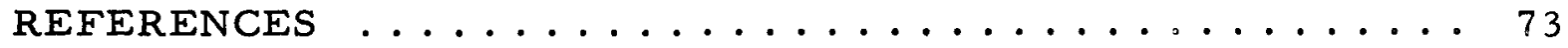




\section{INTRODUCTION}

A quantitative knowledge of the resonance captures in $\mathrm{Th}^{232}$ is essential to the optimum design of thorium converter reactors, particularly those which will be operated for high burnup. It is desirable to determine thorium resonance captures under a broad range of conditions of interest to within the accuracy reasonably attainable by activation techniques, that is, about $\pm 3 \%$.

Two types of integral measurements are desirable in order to achieve a thorough understanding of thorium resonance captures in the complex reactor situation. The first measurement is that of the thin-limit, $1 / E-$ spectrum value, which is the atomic resonance integral, $\int \sigma_{\text {res }}(d E / E)$, for thorium. Since this quantity is simply related to the resonance parameters, its measurement provides a check of these parameters (resonance-parameter values are required to predict the resonance captures in any reactor condition). The second type of measurement is the resonance-capture rate in a reactor geometry having large self-shielding of the resonances. This second measurement together with the first provides an experimental check of the methods of computation of both the self-shielding and the reactor spectrum.

The thin-limit, l/E-spectrum measurement of the atomic resonance integral of $\mathrm{Th}^{232}$ is neither new nor unique to the Peach Bottom HTGR. Integral measurements of this quantity have already been made several times, but with results which differ from one another by nearly a factor of two. * Furthermore, there are significant uncertainties in the values of several important resonance parameters. Because of the se uncertainties, the thin-limit, I/E-spectrum case has been remeasured as part of the

\footnotetext{
* See, for example, the results given in Refs. 2 and 3.
} 
Peach Bottom HTGR development program.

Measurements in the HTGR geometry had not been previously made for either $\mathrm{Th}^{232}$ or $\mathrm{U}^{238}$. They were carried out in this program with thorium in oxide form dispersed quasi-homogeneously through about onequarter of the graphite of the core. Measurements were made with this thorium-graphite mixture in two annular arrangements, one annulus larger than the other, and in one cylindrical arrangement in the HTGR critical as sembly.

A new technique of measurement termed the vanadium-subtraction technique, described in Ref, l, has been principally applied in this work. An essential feature is the determination and subtraction of the activations in the $1 / \mathrm{v}$ cross-section component of an unknown nuclide through an auxiliary measurement. A nuclide having suitable activation characteristics and a cross section close to a $1 / v$ energy dependence is required. The element chosen to provide these characteristics in the se measurements was $\mathrm{V}^{5 \mathrm{l}}$ contained in natural vanadium.

The principal reason for development of this technique was the difficulty in applying the cadmium-ratio methods of measurement to the HTGRtype quasi-homogeneous dispersal of thorium in graphite. The most satisfactory cadmium-ratio technique ${ }^{(4)}$ requires a large cadmium shield around the thorium-containing region in the reactor. This method cannot be applied to the HTGR because the graphite moderator would remain inside the shield, which would modify the reutron spectrum and invalidate the interpretation of the measurement. The cadmium-ratio technique can be used in making the HTGR measurements if the thorium detector itself is cadmium-shielded. This has been done in making some auxiliary measurements in the void spaces of the HTGR critical assembly; however, the use of cadmium shields on thin detector foils has been shown by experiment to be difficult. Furthermore, the cadmium shield on the detector itself leaves doubts as to whether all neutron in-streaming through cracks in the shield has been eliminated. Even slight streaming of this sort can cause a significant error in the 
results obtained by the cadmium-ratio method. A final difficulty, discussed in detail in Section 2. 2, is the inherently low accuracy of the cadmiumratio method of measurement in the HTGR spectrum. Because of these disadvantages, the vanadium-subtraction technique ${ }^{(1)}$ was developed, and it has proven to be quite successful in the HTGR application.

The vanadium-subtraction technique measures the resonance-capture rate of an unknown nuclide relative to that of a thin foil of $\mathrm{Au}^{197}$, which is taken to be known.

Measurements of the activation of thorium have been made with two types of detector: The principal thorium detector used was a metallic foil. In addition, in several cases, the thorium oxide itself, dispersed in graphite and exposed in the HTGR critical assembly, has been used as a detector. This was done by grinding up and collecting the thorium-containing material after exposure, and measuring the induced radioactivity. This second method of detection is referred to as the "compact-grind" method.

In order to check the technique and to assure internal consistency, several auxiliary measurements have been made. Resonance integrals of $\mathrm{U}^{238}$ and $\mathrm{Mn}^{55}$ have been measured in the $1 / \mathrm{E}$ spectrum. In the criticalassembly triflutes, which are the voids between fuel tubes, resonancecapture rates of thorium and vanadium have been measured using both the cadmium-ratio and the vanadium-subtraction techniques. The resonance integral of vanadium was studied by the cadmium-ratio technique in order to determine the deviation from $1 / \mathrm{v}$ cross-section behavior.

Two general classes of calculations have been carried out in this program. The first class of calculations establishes the quantitative information that must be known in order to reduce the measurements to a numerical result for the thorium (or other unknown) resonance-capture reaction rate. This information includes foil-detector resonance self-shielding and neutron-spectra determinations, so that the $\mathrm{Au}{ }^{197}$ resonance-capture rate can be determined. The results obtained from the measurements together with these data-reducing calculations are termed the measured values. 
The second class of calculations determines the resonance-capture rate in thorium from knowledge of resonance parameters and calculated neutron spectra by means of computational procedures for self-shielded cases currently in use at General Atomic. The value thus obtained is considered to be the calculated value of the resonance-capture reaction rate of thorium (or other element). Comparison with the measured value provides a check of the resonance parameters and the method of calculation.

Section II describes the principle of the measurements and gives results of the data-reducing calculations. Section III describes knowledge of the thorium resonance parameters and methods of calculation of resonance capture which are in use at General Atomic. Sections IV through VIII give results, and Section IX discusses the significance of these results. 


\section{METHODS OF MEASUREMENT AND REDUCTION \\ OF MEASURED DATA}

\section{1. THE VANADIUM-SUBTRACTION TECHNIQUE}

The vanadium-subtraction technique ${ }^{(1)}$ is based on carrying out neutron-induced activations on six samples, in the following manner:

1. Simultaneous activation, in the neutron spectrum of interest, of thin foils of Aul97, vanadium, and the nuclide whose resonance captures are to be measured.

2. Simultaneous activation of similar foils of the same three nuclides in a Maxwellian neutron spectrum of a thermal column.

All foils are arranged to integrate the activation over the geometry of the exposure. For example, the foil detectors used in the exposures in a cylindrical annulus in the critical assembly have the shape of a sector of this annulus which is bounded by two radii.

In addition to the foil detector used for thorium, some measurements have been made by exposing the $\mathrm{ThO}_{2}$ dispersed in graphite in an annulus and observing its action after grinding and collecting. This is the "compactgrind" detection method.

During each exposure, care is taken to keep the flux constant to within a few per cent. Both exposures are simultaneously made and are terminated by shutdowns that occur within a second or less (this time difference is short compared with the decay time of any induced radiation).

Radiation is counted from the six activated samples. The pairs of foils for each nuclide decay in the same manner. The quantity $A^{S} / A^{M}$, which is the ratio of the activations in the spectrum of interest (S) to activations in a Maxwellian spectrum (M), therefore remains constant in time and is determined repeatedly at several convenient times after irradiation. Furthermore, the radiation observed following the activation of $\mathrm{Au}^{197}$ and the unknowns is emitted in each particular case from a single nuclide whose 2200 -meter/sec cross section, $\sigma_{2200}$, is known. This follows from the specific nature of the radiation from each material, and from the discrimination properties of the counter that was used in the detection. 
The ratio of resonance activation of an unknown, $x$, to that of $\mathrm{Au} 197$ is determined from the measured activation ratios by the following relationship:

$$
\frac{\left(A_{\text {res }}\right)_{x}}{\left(A_{\text {res }}\right)_{A u}}=\frac{\left(g \sigma_{2200}\right)_{x}}{\left(g^{\sigma} 2200\right)_{A u}} \frac{\frac{A_{x}^{S}}{A_{x}^{M}}-\frac{K}{g_{x}} \frac{A_{V}^{S}}{A_{V}^{M}}}{A_{A u}^{M}}-\frac{K}{g_{A u}} \frac{A_{V}^{S}}{A_{V}^{M}},
$$

where $A_{\text {res }}$ designates the unnormalized resonance-capture reaction rate, which is defined to be the total reaction rate reduced by the captures in a $1 / v$ cross-section component; $g$ is the Westcott-type ${ }^{(5)}$ spectrum factor for a Maxwellian spectrum, which is required to obtain the relative reaction rate for a cross section which deviates somewhat from $1 / \mathrm{v}$ behavior; and $\mathrm{K}$ is a spectrum-dependent factor ${ }^{\dagger}$ of the order of 0.9 which corrects for the small resonance captures in vanadium. The meaning and derivation of Eq. (1) are described in the remainder of this section.

Let the capture cross section of each nuclide be decomposed into a $1 / v$ component, $\sigma_{1 / v}$, and a resonance component, $\sigma_{\text {res }}$. The former is defined to be so normalized as to give the entire 2200-meter/sec (0.0253-ev) cross section. The resonance cross section is therefore defined to be the excess after $\sigma_{1 / v}$ is subtracted from the total absorption cross section, $\sigma$; that is,

$$
\sigma_{\text {res }}(E)=\sigma(E)-\sigma_{1 / v}(E)=\sigma(E)-\sigma_{2200} \sqrt{\frac{0.0253}{E}} .
$$

Let $\phi^{S}$ designate the neutron flux in a spectrum, S, of interest. $\phi S$ can be a spectrum having $1 / \mathrm{E}$-dependence above about $0.5 \mathrm{ev}$, an unshielded reactor spectrum, or a cadmium-shielded reactor spectrum, and can be expressed in terms of either energy, E, or lethargy, $u$, as an independent

* Ares is specifically defined in Eq. (16).

$\dagger_{K}$ is defined in Eq. (14). 
variable. The conventional relations apply between these two choices; namely,

$$
\begin{aligned}
u & =\ln \frac{10^{7}}{E} \quad(E \text { in ev), } \\
\phi^{S}(u) & =E \phi^{S}(E) .
\end{aligned}
$$

The capture reaction rate in a portion of the spectrum, for each choice of independent variable, is

$$
\mathrm{dA}=\phi(E) \sigma(E) \mathrm{dE},
$$

or

$$
d A=\phi(u) \sigma(u) d u
$$

The capture reaction rate over the spectrum interval $E_{1}$ to $E_{2}$ is

$$
A=\int_{E_{1}}^{E_{2}} \phi(E) \sigma(E) d E,
$$

or

$$
A=\int_{u\left(E_{2}\right)}^{u\left(E_{1}\right)} \phi(u) \sigma(u) d u
$$

For a $1 / E$ spectrum, having $\phi(u)$ constant, Eqs. (5) are

$$
A=\int_{E_{1}}^{E_{2}} \sigma(E) \frac{d E}{E}
$$

or

$$
A=\int_{u\left(E_{2}\right)}^{u\left(E_{1}\right)} \sigma(u) d u .
$$

Equations (6) have the form of the resonance integral. The specific definition adopted in this work for the thin-limit resonance integral is that form 
of Eqs. (6) with contributions of $\sigma_{1 / v}$ removed, or with $\sigma$ replaced by $\sigma_{\text {res; }}$; that is,

$$
\begin{aligned}
& I=\int_{E_{1}}^{E_{2}} \sigma_{r e s}(E) \frac{d E}{E} \\
& I=\int_{u\left(E_{1}\right)}^{u\left(E_{2}\right)} \sigma_{r e s}(u) d u .
\end{aligned}
$$

The resonance integral is the capture rate in the resonance cross-section component in the particular spectrum having a $1 / E$ energy dependence, and with the spectrum normalized so that $\phi^{S}(u)=1$.

In much of the following analysis the arguments of $\phi^{S}$ and the $\sigma$ values are omitted, and the independent variable is understood to be $E$ or $u$ according to whether the differential $d E$ or $d u$ is written.

Let $\phi^{M}$ designate the Maxwellian neutron-flux spectrum. The activation of a detector foil per unit mass of the ith material in $\phi^{M}$ is

$$
A_{i}^{M}=(N \epsilon)_{i} \int \phi^{M}\left(\sigma_{1 / v}+\sigma_{r e s}\right)_{i} d u
$$

or

$$
A_{i}^{M}=\frac{\sqrt{\pi}}{2}(N \in g)_{i}\left(\sigma_{2200}\right)_{i} \phi^{M} d u \text {. }
$$

where $N_{i}$ is the number of atoms per unit weight of the foil, and $\epsilon_{i}$ is the efficiency of the counter used to measure the activation of the ith detector. Equation ( $8 \mathrm{~b})$ is the definition of the Westcott's Maxwellian spectrum factor $g_{i}^{5}$, which is unity if $\sigma_{\text {res }}$ is exactly zero at all energies where the Maxwellian flux is significant. For applications of present interest, all $g_{i}$ values are shown in Section 2.3 to be unity to within a few tenths of one per cent.

The activation of a detector foil in the spectrum $\phi^{S}$ is

$$
A_{i}^{S}=(N \epsilon)_{i} \int \phi(u)\left[\sigma_{1 / v}(u)+f_{r e s}(u) \sigma_{r e s}(u)\right]_{i} d u,
$$


where the resonance self-shielding factor, $f_{r e s}(u)$, must be included in the analysis. The detector foils whose characteristics are described in Section 2.3 are sufficiently thin that self-shielding is of negligible concern, except for the big resonances. However, for these big resonances, selfshielding corrections of several per cent are necessary. It is sufficient with detector foils of small self-shielding to treat these self-shielding corrections by a single multiplicative factor for the entire resonance region, which is assumed to be the same in all spectra and which can therefore be evaluated in a $\mathrm{l} / \mathrm{E}$ spectrum. The second term of Eq. (9) is therefore replaced by

$$
\left(N \in f_{r e s}\right)_{i} \int \phi^{S}(u)\left[\sigma_{r e s}(u)\right]_{i} d u,
$$

where

$$
\left(f_{r e s}\right)_{i}=\frac{\int\left[f_{r e s}(u) \sigma_{r e s}(u)\right]_{i} d u}{\int\left[\sigma_{r e s}(u)\right]_{i} d u} .
$$

The first term of Eq. (9) depends only on $\phi^{S}$ and $\sigma_{2200}$ through the relation between $\sigma_{1 / v}$ and $\sigma_{2200}$ for each nuclide, and it is therefore proportional to $A_{i}^{M} / g_{i}$. Equations (9) and (10) can therefore be written

$$
A_{i}^{S}=C \frac{A_{i}^{M}}{g_{i}}+\left(N \in f_{r e s}\right)_{i} \int \phi^{S}\left(\sigma_{r e s}\right)_{i} d u,
$$

where $\mathrm{C}$ is a constant of proportionality which is the same for each nuclide. Division of Eq. (9a) by Eq. (8) eliminates the unknown $(\mathrm{N \epsilon})_{i}$ :

$$
\left(f_{\text {res }}\right)_{i} \int \phi^{S} \sigma_{\text {res }} d u=\frac{\sqrt{\pi}}{2}\left(g \sigma_{2200}\right)_{i} \int \phi^{M} d u\left(\frac{A_{i}^{S}}{A_{i}^{M}}-\frac{C}{g_{i}}\right) \text {. }
$$


According to Eq. (9a), C is

$$
C=\frac{A_{1 / v}^{S}}{A_{1 / v}^{M}}
$$

where the A terms are the activations of an absorber having an ideal $1 / \mathrm{v}$ cross section. Actually, $A_{1 / v}^{S} / A_{1 / v}^{M}$ cannot be measured exactly by activation in any known material, because of the contributions from the resonance component of the cross section. In vanadium, however, this resonance component contributes only a few per cent of the activations in spectrum $\phi^{S}$, and none in $\phi^{M}$. C is therefore determined somewhat indirectly by measuring $A_{V}^{S} / A_{V}^{M}$ to simulate $A_{1 / v}^{S} / A_{1 / v}^{M}$, and then correcting $A_{V}^{S}$ to $A_{1 / v}^{S}$ from knowledge of the relative importance of the resonance and $1 / v$ component of the vanadium cross section. Let the required correction factor be defined as follows:

$$
K=\frac{A_{1 / v}^{S}}{A_{V}^{S}}=\frac{\int \sigma_{1 / v, V} \phi^{S} d u}{\int \sigma_{V} \phi^{S} d u} .
$$

Eq. (13) can be finally expressed in terms of cross sections, as follows:

$$
K=\frac{1}{1+\frac{\int^{\sigma}{ }_{\text {res }, v^{\phi}} \phi^{S} d u}{\int \sigma_{1 / v, v} \phi^{S} d u}} .
$$

C of Eq. (11) is then to be eliminated by the following relation:

$$
C=K \frac{A_{V}^{S}}{A_{V}^{M}}
$$

where the activation ratio of Eq. (15) is to be measured. The second term in the denominator of Eq. (14) is calculated in Section 5 from a combination of measured information concerning vanadium resonance capture, described in Section 4.2, and calculated spectral information concerning $\phi$. The pertinent spectral quantities are defined in Section 2. 5.

\footnotetext{
* $g$ and the self-shielding factors for the vanadium foil are unity.
} 
Equation (1) is then obtained from the ratio of two equations of the form of Eq. (11), one for an unknown and one for $\mathrm{Au}{ }^{197}$, with $\mathrm{C}$ eliminated by Eq. (15):

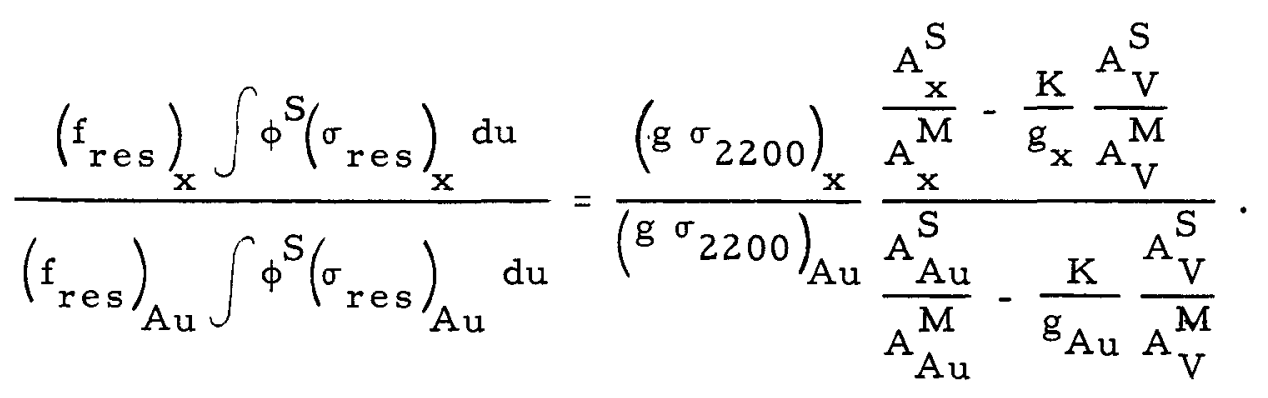

This equation is just Eq. (1), since the resonance reaction rate, $\left(A_{r e s}\right)_{i}$, is

$$
\left(A_{\text {res }}\right)_{i}=\left(f_{\text {res }}\right)_{i} \int \phi\left(\sigma_{\text {res }}\right)_{i} d u .
$$

Since ratios are used in Eq. (1), this reaction rate can be normalized to any flux level. The normalization adopted in this work to compare calculations with measurements is given in Section 2. 5 .

Several points about this vanadium-subtraction activation method are noteworthy:

1. An essential feature is the simultaneous exposure of foils of an unknown, of $\mathrm{Au}^{197}$, and of vanadium in each of the fluxes, $\phi \mathrm{S}$ and $\phi^{\mathrm{M}}$, so that $\mathrm{C}$ is the same for each nuclide.

2. The poorly known 2200 -meter/sec activation cross section of vanadium is not required in the analysis.

3. An auxiliary measurement is required to determine $K$, since the resonance integral of vanadium has not yet been measured. This measurement and the resulting determination of $\mathrm{K}$ are described in Section V.

4. For an infinitesimally thin detector in a $1 / E$ spectrum, Eq. (16) gives a resonance reaction rate which is the resonance integral with the "l/v tail" subtracted. 
The quantity measured by the vanadium-subtraction technique is that usually quoted by the Swedish group ${ }^{(6)}$ as the resonance integral. A more common definition of the resonance integral (7) includes the "1/v tail" above the cadmium cutoff energy. The difference between these alternative definitions is the quantity

$$
2 \sqrt{0.0253 / E_{C d}}\left(\sigma_{2200}\right),
$$

where $\mathrm{E}_{\mathrm{Cd}}$ is the cadmium cutoff energy. This difference is about $35 \mathrm{~b}$ in the case of $\mathrm{Au}{ }^{197}$ and more than $3 \mathrm{~b}^{* 6}$ in the case of $\mathrm{Th}^{232}$.

\section{2. THE CADMIUM-RATIO TECHNIQUE}

The cadmium-ratio technique has been employed to obtain a semiquantitative measurement of the resonance capture rate of vanadium, $\mathrm{Mn}^{55}$, and $\mathrm{Th}^{232}$ foils placed in a void in the HTGR critical as sembly. This was done for vanadium because no measurements of its resonance integral have been reported previously. The measurements for $\mathrm{Mn}^{55}$ and $\mathrm{Th}^{232}$ were made for comparison with results obtained by the vanadiumsubtraction technique.

The cadmium-ratio technique can be seen to be inherently less accurate for making measurements in HTGR spectra than the vanadium-subtraction technique. Results obtained for these measurements by the cadmium-ratio method should be considered to have an accuracy of about $\pm 10 \%$. Reasons for this relatively poor accuracy are discussed below.

The familiar cadmium-ratio method described by Macklin and Pomerance ${ }^{(7)}$ measures C. R., the cadmium ratio of two foils, and determines the ratio of epicadmium reaction rates from these measurements by means of the following relation:

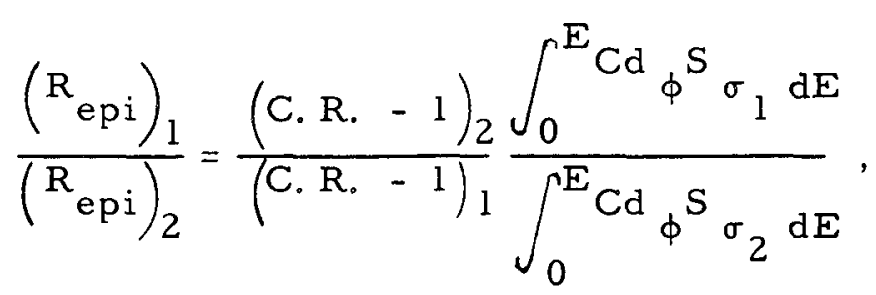

The "deviation from 1/v dependence," discussed in Sections 3.1 and 7.2 , reduces this difference to about $2.5 \mathrm{~b}$ in the case of $\mathrm{Th} 232$. 
where $R_{e p i}$ is the epicadmium reaction rate above the cadmium cutoff energy, ${ }_{C d}$, and the quantity

$$
\int_{0}^{E} C d \phi^{S} \sigma d E
$$

is a subcadmium reaction rate. Equation (17) is applied to relate the $R_{e p i}$ values of an unknown to that of a known quantity, usually taken to be $\mathrm{Au}^{197}$. For the HTGR, the C. R. of $\mathrm{Au}^{197}$ is 1.20 or less. C. R. can be measured to within about $\pm 1 \%$. This leaves an uncertainty of $\pm 5 \%$ in the quantity (C. R. - 1) of $\mathrm{Au}^{197}$, which makes $\mathrm{R}_{\text {epi }}$ of Eq. (17) uncertain by $\pm 5 \%$.

Further loss of accuracy can occur in determining the resonancereaction-rate component of $\mathrm{R}_{\text {epi }}$, particulary for vanadium. The $1 / \mathrm{v}$ cross-section component absorbs about $95 \%$ of the epicadmium captures in the case of vanadium. The determination of the $\sigma_{\text {res }}$ capture component of Eq. (14) for vanadium from Eq. (17) therefore involves two separate instances of small differences of nearly equal numbers, leading to a result having the accuracy of only an estimate.

A further complication in applying Eq. (17) with $\mathrm{Au}^{197}$ as a standard is that its subcadmium cross section deviates significantly from $1 / \mathrm{v}$ behavior. For this reason $E_{\mathrm{Cd}}$ for $\mathrm{Au}^{197}$ is significantly larger $(8)^{* *}$ than that of the other nuclides that have $1 / v$-like cross sections, and it is more sensitive to the subcadmium neutron spectrum. The se peculiarities of $\mathrm{Au}^{197}$ make the ratio of integrals on the right side of Eq. (17) different by about $5 \%$ from the ratio of 2200-meter/sec cross sections. A quantitative application of Eq. (17) requires good knowledge of $\phi^{S}$ and careful evaluation of the integrals. This difficulty considerably lessens the usefulness of the technique of measuring resonance captures by comparing the cadmium ratio of an unknown with that of $\mathrm{Au}^{197}$. The principal advantage of the measurement procedure described by Macklin and Pomerance ${ }^{(7)}$ is that, for materials having cross sections with a $1 / \mathrm{v}$ dependence up to about $1 \mathrm{ev}$, the ratio of integrals in Eq. (17) is the same as the ratio of the $2200-$ meter/sec cross sections, so

\footnotetext{
*See particularly Table III, p. 344 of Ref. 8.
} 
that evaluation of these integrals can be avoided. However, this advantage is not applicable when ratios are taken relative to $\mathrm{Au}^{197}$.

Because of these complications, the method adopted in this work determines the ratio of resonance captures of an unknown to its subcadmium captures, which are considered to be known. No reference to the properties of $\mathrm{Au}{ }^{197}$ is involved. To accomplish this, two quantities characteristic of the low-energy spectrum are required. These have been carefully calculated by a method based on a realistic and thorough treatment of the neutron spectrum. (9) This method of calculation has shown excellent agreement ${ }^{\text {(9) }}$ with spectra which have been measured for very similar cases. The two spectral quantities chosen are (C. R. $)_{1 / v}$ and $T$. The quantity (C. R.) $1 / v$ is the cadmium ratio of a $1 / \mathrm{v}$ absorber. $\mathrm{T}$ is proportional to the absorption rate in a $1 / v$-cross-section component above the cadmium cutoff and is defined as follows:

$$
T \sigma_{2200}=\frac{1}{\phi^{S}(1 \mathrm{ev})} \int_{E_{C d}}^{\infty} \phi^{S} \sigma_{1 / v} d E
$$

$\mathrm{T}$ is nearly the same for each spectrum of present interest, so that it is well known. (C. R. $)_{1 / v}$ is considered to be determined from the quantitative spectrum calculations to within about $\pm 5 \%$.

Consider the relation of C. R. of any particular nuclide, other than gold, to the resonance reaction rate and defined spectral quantities for this nuclide:

C. $R$. =

$$
\frac{\int_{0}^{E_{C d} S} \phi^{S} \sigma_{1 / v} d E+\int_{E}^{\infty} \phi^{S} \sigma_{1 / v} d E+f_{r e s} \int_{E}^{C d} \phi^{S} \sigma_{r e s} d E}{\int_{E}^{\infty} \phi^{S} \sigma_{1 / v} d E+f_{r e s} \int_{E}^{\infty} \phi_{C d}^{S} \sigma_{r e s} d E},
$$


since the nuclides of interest have a negligible $\sigma_{\text {res }}$ component at energies less than $E_{C d}$. Upon division of numerator and denominator by $\phi(1 \mathrm{ev})$, Eq. (19) becomes

C.R. =

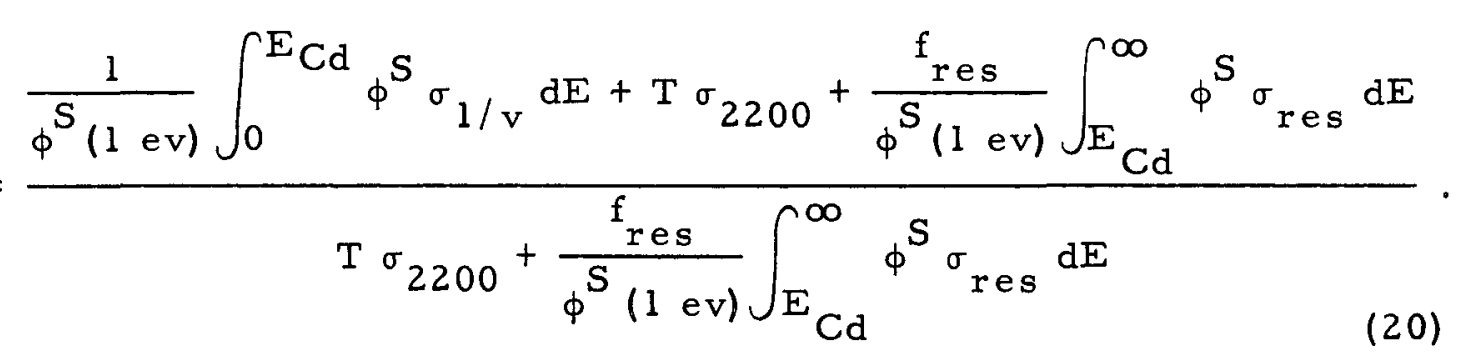

For a $1 / \mathrm{v}$ nuclide, Eq. (20) gives

$$
\frac{1}{\phi^{S}(1 \mathrm{ev})} \int_{0}^{E} \mathrm{Cd} \phi_{\sigma_{1 / v}} \mathrm{dE}=\left[\left(\mathrm{C} . \mathrm{R}^{\mathrm{S}}\right)_{1 / \mathrm{v}}-1\right] \mathrm{T} \sigma_{2200^{\circ}}
$$

The combination of Eqs. (20) and (21) enables one to obtain the resonance reaction rate as follows:

$$
\frac{\int \phi^{S}{ }_{r e s}^{x} d E}{\phi(1 \text { ev })}=\frac{1}{f_{r e s}^{x}} \frac{(\text { C. R. })_{1 / v}-(C . R .)}{(C . R .)_{x}-1} T \sigma_{2200}^{x}
$$

Equation (17) was found to give results in agreement with those obtained by means of Eq. (22) to within the errors discussed previously.

A limitation to the accuracy of the determination of resonance capture rates by means of Eq. (22) results from the difference of C. R. 's in the numerator, each of which may be in error by several per cent. The accuracy is such that the resonance reaction rates of $\mathrm{Mn}^{55}$ and vanadium are determined to within about $\pm 10 \%$ and $\pm 50 \%$, respectively. The measurements of Section $\mathrm{V}$ show the resonance captures of vanadium to be only a few per cent of its $1 / \mathrm{v}$-component captures. Since this resonance component of vanadium is measured to be small in any case, it is not necessary to improve the $\pm 50 \%$ accuracy in its determination. 
In the analysis, a renormalized version of Eq. (22), designated Eq. (22a) and described in Section 2. 5, is applied.

\section{3. CALCULATION OF DETECTOR-FOIL CHARACTERISTICS}

The resonance self-shielding factors, $f_{r e s}$, and the Maxwellianspectrum $\mathrm{g}$ factors have been carefully calculated for the detector foils.

The $f_{\text {res }}$ were found by first determining the resonance integral of a slab of the same thickness as the detector foil and then comparing this value with the value for an infinitesimally thin slab; the resulting ratio is $f_{\text {res }}$ The best available integral-equation method $(10-13)^{*}$ of calculation was applied. The approximately known values of the resonance parameters which were used are adequate to quantitatively determine the relative captures in a practical foil compared with the limit of a very thin foil. For $\mathrm{Au}^{197}$ and $\mathrm{Mn}^{55}$, which have about $90 \%$ of captures in the lowest resonance, at $4.91 \mathrm{ev}$ and $337 \mathrm{ev}$, respectively, the self-shielding of only this dominant resonance was determined and was then applied as appropriate for the entire resonance region. For $\mathrm{Th}^{232}$, the resolved resonances up to about $1000 \mathrm{ev}$ were considered in determining foil self-shielding.

The Maxwellian-spectrum $\mathrm{g}$ factors are in close agreement with values that have been given by Westcott. (14) values for $\mathrm{Au}{ }^{197}$ and $\mathrm{Th}^{232}$. In the case of $\mathrm{Au}{ }^{197}$, measurements made at Columbia University ${ }^{(15) t}$ of the low-energy cross-section dependence were used. For $\mathrm{Th}^{232}$, the cross-section description of Garrison ${ }^{(16)}$ discussed in Section III was applied.

The characteristics of metallic detector foils, including calculated values of $\mathrm{f}_{\text {res }}$ and $\mathrm{g}$, are given in Table 1 . In the case of $\mathrm{Th}^{232}$, two different thicknesses of detector foils were used, the thicker foil having been used in measurements for the large-annulus geometry and the thinner foil in all other measurements. The characteristics of both foils are given in Table 1.

*In Ref. 10, see Sections 3 and 4, in particular.

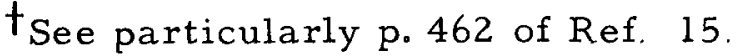


Table 1

CHARACTERISTICS OF DETECTOR FOILS

\begin{tabular}{|c|c|c|c|c|}
\hline $\begin{array}{l}\text { Principal } \\
\text { Nuclide }\end{array}$ & $\begin{array}{c}\text { Mass of } \\
\text { Principal } \\
\text { Nuclide } \\
\left(\mathrm{mg} / \mathrm{cm}^{2}\right)\end{array}$ & $\begin{array}{c}\sigma_{2200} \\
\text { (barns) }\end{array}$ & $\begin{array}{l}\text { Resonance } \\
\text { Self-shielding } \\
\text { Factor, fres }\end{array}$ & $\begin{array}{l}\text { Maxwellian- } \\
\text { spectrum } \\
\text { Factor, } g\end{array}$ \\
\hline $\mathrm{Au}^{197}$ & 0.17 & 98.8 & 0.980 & 1.003 \\
\hline Vanadium & 76 & 4.5 & 1.00 & 1.00 \\
\hline $\mathrm{Th}^{232}$ & $\left\{\begin{array}{l}3.3 \frac{\mathrm{a}}{} \\
4.24 \underline{\mathrm{b}}\end{array}\right.$ & $\begin{array}{l}7.45 \\
7.45\end{array}$ & $\begin{array}{l}0.966 \\
0.959\end{array}$ & $\begin{array}{l}1.002 \\
1.002\end{array}$ \\
\hline$U^{238}$ & 0.85 & 2.75 & 0.974 & 1.00 \\
\hline $\mathrm{Mn}^{55}$ & 3.3 & 13.2 & 0.955 & 1.00 \\
\hline
\end{tabular}

$\underline{a}$ Used for most measurements.

$\underline{b}$ Used for large-annulus measurements only.

All the foils were sufficiently thin that $2200-$ meter/sec cross-section self-shielding factors were within about $0.1 \%$ of unity. Consequently, lowenergy self-shielding factors were neglected. The $f_{r e s}$ for the compactgrind method is determined by the grain size of the thorium oxide particles contained in the compact. For most exposures in which the grain size was 40 microns or less, this grain self-shielding was negligible. The largeannulus exposure, in which the average grain size was 237 microns, was calculated to give a value of 0.94 for $f_{\text {res }^{\circ}}$

2. 4. ABSORPTION CROSS SECTION OF $\mathrm{Au}^{197}$

The following information has been used to determine absorptions in $\mathrm{Au}^{197}$, which was taken as the standard of reference in these measurements.

Columbia measurements of the resonance parameters ${ }^{*}$ have been adopted. These values are given in Table 2. For energies up to $37 \mathrm{ev}$, where the cross section is dominated by the 4.91 -ev resonance, $\sigma_{n, \gamma}$ is *Results of these measurements are reported in Ref. 17. 
taken to be a sum of the contribution from the dominant resonance and a residual $1 / \mathrm{v}$ component arising from higher-energy resonances. This gives, for $0 \leq \mathrm{E} \leq 37 \mathrm{ev}$,

$$
\left(\sigma_{n, \gamma}\right)_{A u 197}=32.85 \times 10^{3} \sqrt{\frac{4.91}{E}} \frac{1}{\left(\frac{E-4.91}{0.0698}\right)^{2}+1}+\frac{0.8591}{\sqrt{E}} .
$$

Each resolved resonance lying between 47 and 940 ev has been treated as having $\delta$-function ${ }^{*}$ absorption of a strength necessary to give the thin-limit resonance integral predicted by the resonance parameters of Table 2 , which uses the standard notation of BNL-325. ${ }^{(18)}$ Since these resonances are narrow and the detector foil self-shielding is negligible for all but the $4.91-\mathrm{ev}$ resonance, this mathematically idealized treatment is correct for these higher resonances. Additional resonances of $\mathrm{Au}^{197}$ are listed in Table 3.

In the energy region above $940 \mathrm{ev}, \sigma_{n, \gamma}$ is treated on a statistical basis using the averages of the parameters listed in Table 2,as follows:

$$
\begin{aligned}
\bar{D} & =21.1 \mathrm{ev} \\
\overline{\Gamma_{\gamma}} & =0.196 \mathrm{ev} \\
\overline{\Gamma_{\mathrm{n}}^{0}} & =0.0051 \mathrm{ev} \\
\overline{\mathrm{g}} & =1 / 2
\end{aligned}
$$

Two approximations are made in treating this region, namely, neglect of the reduction due to the Porter-Thomas distribution and neglect of the increase due to $\lambda>0$ contributions. The net effect of these approximations is probably an overestimate of the resonance integral by about $2 \mathrm{~b}$, which is a negligible fraction of its total.

*The $\delta$-function is P. A. M. Dirac's mathematical idealization of a narrow, peaked function of given area under the curve. The idealization considers the function to be taken to a limit having infinitesimal width and infinite height in a manner such that the area under the curve, or "strength," remains constant. 
Table 2

MEASUREMENTS OF Au ${ }^{197}$ RESONANCE PARAMETERS (Data taken from Ref. 17)

\begin{tabular}{|c|c|c|c|c|}
\hline $\begin{array}{c}E_{0} \\
(e v)\end{array}$ & $\mathrm{g}$ & $\begin{array}{c}\Gamma_{\mathrm{n}} \\
\left(10^{-3} \mathrm{ev}\right)\end{array}$ & $\Gamma_{n}^{0}\left(10^{-3}(\mathrm{ev})^{1 / 2}\right)$ & $\begin{array}{c}\Gamma_{\gamma} \\
\left(10^{-3} \mathrm{ev}\right)\end{array}$ \\
\hline 4.91 & $5 / 8$ & 15.6 & 7.0 & 124 \\
\hline 46.7 & & 0.11 & 0.016 & \\
\hline 58.2 & & 4. 7 & 0.62 & 143 \\
\hline 60.3 & $5 / 8$ & 76.0 & 9.8 & 120 \\
\hline 78.7 & & 13.0 & 1. 46 & 145 \\
\hline 107.3 & & 9.3 & 0.9 & 165 \\
\hline 122.6 & & 0.8 & 0.07 & \\
\hline 144.8 & & 6.5 & 0.54 & 190 \\
\hline 151.8 & $5 / 8$ & 23.2 & 1.9 & 179 \\
\hline 163.6 & & 40.0 & 3.1 & \\
\hline 165.6 & & 12.0 & 0.9 & \\
\hline 190.8 & $3 / 8$ & 36.0 & 2.5 & 189 \\
\hline 209.6 & & 0.72 & 0.05 & \\
\hline 241.0 & $5 / 8$ & 68.0 & 4.4 & 185 \\
\hline 256.2 & & 0.6 & 0.37 & \\
\hline 263.4 & $3 / 8$ & 150.7 & 9.3 & 136 \\
\hline 275.0 & & 5.0 & 0.3 & 127 \\
\hline 294.5 & & 400.0 & 23.0 & 250 \\
\hline 330.5 & & 200 & 11.0 & \\
\hline 332.5 & & 60 & 3.2 & \\
\hline 357.0 & $5 / 8$ & 40.8 & 2.2 & 177 \\
\hline 373.0 & & 115 & 5.9 & \\
\hline 377.0 & & 12 & 0.6 & \\
\hline 384.0 & & 90 & 4.6 & \\
\hline 403.0 & & 26 & 1.3 & 590 \\
\hline 442.0 & $3 / 8$ & 306.7 & 15.0 & 280 \\
\hline 453.0 & $3 / 8$ & 120 & 5.6 & 250 \\
\hline 479.0 & & 300.8 & 13.6 & 180 \\
\hline 492.0 & & 45 & 2. 0 & \\
\hline 496.0 & & 15 & 0.7 & \\
\hline 538.0 & & 39 & 1. 7 & 280 \\
\hline 551.0 & & 36 & 1.5 & 282 \\
\hline 565.0 & & 3.3 & 0.14 & \\
\hline 583.0 & & 370 & 15.0 & \\
\hline 590.0 & & 30 & 1.2 & \\
\hline
\end{tabular}


Table 2--continued

\begin{tabular}{|c|c|c|c|c|}
\hline $\begin{array}{l}E_{0} \\
(e v)\end{array}$ & g & $\begin{array}{c}\Gamma_{\mathrm{n}} \\
(10-3 \mathrm{ev})\end{array}$ & $\begin{array}{c}\Gamma_{n}^{0} \\
\left(10^{-3}(\mathrm{ev})^{1 / 2}\right)\end{array}$ & $\begin{array}{c}\Gamma_{\gamma} \\
\left(10^{-3} \mathrm{ev}\right)\end{array}$ \\
\hline 606.0 & $5 / 8$ & 198.4 & 8.0 & 140 \\
\hline 621.0 & $3 / 8$ & 110.7 & 4.4 & 160 \\
\hline 628.0 & & 60 & 2. 4 & \\
\hline 632.0 & & 35 & 1.4 & \\
\hline 644.0 & $3 / 8$ & 653.3 & 25.0 & 270 \\
\hline 664.0 & & 6.2 & 0.24 & \\
\hline 691.0 & & 10 & 0.38 & \\
\hline 702.0 & & 400 & $\sim 15.0$ & \\
\hline 706.0 & & 240 & $\sim 9.0$ & \\
\hline 721.0 & $5 / 8$ & 86.4 & 3.2 & 210 \\
\hline 743.0 & & 11 & 0.4 & \\
\hline 766.0 & $3 / 8$ & 426.7 & 15.3 & 154 \\
\hline 781.0 & & 148 & 5.3 & \\
\hline 791.0 & & 125 & 4.4 & 170 \\
\hline 803.0 & $3 / 8$ & 285.3 & 10.0 & 217 \\
\hline 819.0 & & 40 & 1.4 & \\
\hline 825.0 & & 150 & 5 & \\
\hline 831.0 & & 150 & 5 & \\
\hline 871.0 & & 16 & 0.54 & 150 \\
\hline 886.0 & & 65 & 2.2 & 125 \\
\hline 940.0 & $5 / 8$ & 434.4 & 14.2 & 110 \\
\hline
\end{tabular}

Table 3

ADDITIONAL $E_{0}$ VALUES OBSERVED FOR Au 197 (In ev)

(Data taken from Ref. 17)

\begin{tabular}{rllllll}
\hline 968 & 1137 & 1297 & 1465 & 1660 & 1905 & 2220 \\
993 & 1140 & 1323 & 1485 & 1712 & 1935 & 2250 \\
998 & 1194 & 1340 & 1505 & 1725 & 1965 & 2270 \\
1002 & 1217 & 1347 & 1514 & 1740 & 1995 & 2315 \\
1047 & 1228 & 1367 & 1545 & 1752 & 2055 & 2360 \\
1072 & 1232 & 1375 & 1566 & 1775 & 2105 & 2395 \\
1086 & 1255 & 1408 & 1595 & 1825 & 2140 & 2440 \\
1100 & 1265 & 1438 & 1610 & 1840 & 2155 & 2470 \\
1130 & 1293 & 1445 & 1630 & 1870 & 2175 & \\
\hline
\end{tabular}


These data lead to the following thin-limit, l/E-spectrum resonance integ ral:

$$
\int_{0}^{\infty}\left(\sigma_{\text {res }}\right)_{A u} 197 \frac{d E}{E}=1526 b
$$

where

$$
\left(\sigma_{\text {res }}\right)_{A u} 197=(\sigma){ }_{A u} 197-98.8 \sqrt{\frac{0.0253}{E}} .
$$

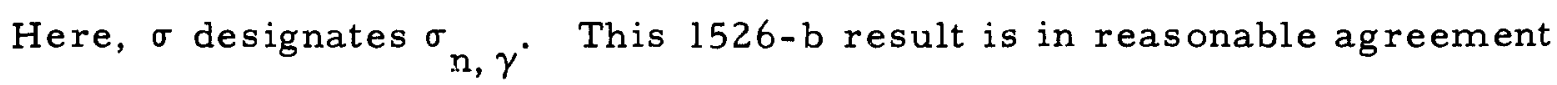
with the $1490 \pm 40 \mathrm{~b}$ result for the same integral from $0.5 \mathrm{ev}$ to infinity which was obtained by Swedish workers ${ }^{(6)}$ who used a cadmium-ratio technique of measurement. The absorption rate of $\mathrm{Au}^{197}$ can be used with confidence that it is accurate to with in $\pm 2 \%$. The value adopted in this analysis may be slightly high. The same comments about accuracy apply to the thorium and other resonance reaction rates determined from these measurements relative to these $\mathrm{Au}^{197}$ absorptions.

\subsection{CALCULATION OF REACTOR NEUTRON SPECTRA AND Au 197 RESONANCE-CAPTURE REACTION RATES}

The data-reducing class of calculations includes determination of neutron spectra. These spectra in reactor cores, together with $\mathrm{Au}^{197}$ cross-section data, are required for determination of the resonancecapture rate of $\mathrm{Au}^{197}$, which is used as the standard of reference in the vanadium-subtraction method.

Measurements were made in spectra of the following four basic configurations:

1. A position $2.8 \mathrm{~cm}$ into the water reflector of the TRIGA reactor, i. e., $2.8 \mathrm{~cm}$ beyond the core-reflector interface.

2. HTGR critical assembly core 3 .

3. HTGR critical assembly core 6 .

4. HTGR critical assembly core 7 . 
Exposure in the TRIGA reactor was used to produce a $1 /$ E spectrum in the resonance region. Measurements in this spectrum using the detector foils described in Table 1 have been made to determine thin-limit, $1 / E-$ spectrum resonance integrals.

The activations in the several loadings of the Peach Bottom HTGR critical assembly were carried out near the center of the reactor. The nature of this assembly, the specific core loadings, and the details of the local geometry are described in separate reports. Cores 3 and 6 are versions of the so-called "lattice testing" loadings (described in Ref. 19), in which the annular HTGR geometry was simulated at the center of the core. Core 7 (described in Ref. 20) simulated the neutron events in a simpler geometry having the thorium loaded in a cylindrical arrangement.

In addition, several exposures were made in cores $4 \mathrm{~B}$ and 5 , which had essentially the same spectral characteristics above $1 \mathrm{ev}$ as those of core 6 . In core 5 , the amount of thorium contained in the six annuli surrounding the central annulus was greater than in cores 3 and 6 , so that the $\mathrm{C} / \mathrm{Th}$ ratio in these particular annuli of core 5 was 48.7 (30 wt-\% metal).

Activation exposures were made in the following positions in these as semblies:

1. Central annuli of cores $4 \mathrm{~B}, 5$, and 6 .

2. Buffer cylinder of core 7 .

3. Central triflutes, or void spaces around the central annulus, of cores 3 and 6 .

Calculations of two general types to determine $\phi^{S}$ were carried out. These calculations for a particular $\phi^{S}$ can be designated as. initial-spectrum and multigroup-spectrum calculations.

The initial spectrum is determined by computations of the slowingdown and thermalization distribution made at a point in the reactor. In these calculations, leakage is approximated by a constant buckling, which was estimated initially; other significant physical effects are considered 
to be adequately described. In these initial-spectrum calculations, the solution is obtained in great detail as a function of energy, the broadest lethargy bandwidth being one-quarter of a unit. The energy range down to about $2 \mathrm{ev}$ is handled by the GAM-I code. and degradation realistically and describes thorium resonance absorption by average cross sections determined for each quarter-unit-wide lethargy group. This treatment in each thorium resonance gives the absorptions determined by either the N. R. or I. M. (N. R. I. A.) Wigner resonance integral approximation. $(10)^{*}(22)(23)$ Below $2 \mathrm{ev}$, the GATHER-II code ${ }^{(24)}$ is used; this code computes thermalization on the basis of an advanced and experimentally verified spectrum model.

Initial spectra for HTGR critical as sembly cores 3 and 6 are given in Fig. 1. The spectra of these cores differ to only a negligible extent in the resonance region, above about $2 \mathrm{ev}$, but in the thermal region the borated core, core 6, has a noticeably harder spectrum.

Multigroup spectra have been determined from the output of onedimensional multigroup calculations done for an entire assembly. ${ }^{(25)}$ These calculations have been carried out for HTGR cores 3, 6, and 7, and for the TRIGA reactor. The results obtained for those multigroup spectra in the energy region above several electron volts for each HTGR assembly were very similar, and were consistent with the curve of Fig. I to within a few per cent. Therefore, the resonance-region spectrum of each HTGR core can be taken to be adequately described by the initial spectrum of Fig. 1, although the actual spectra of the final analysis were usually determined by the multigroup calculations.

Figure 2 gives the multigroup-determined spectrum at the position of exposure in the reflector of the TRIGA reactor. These calculations show the energy dependence of this spectrum to be close to $1 / \mathrm{E}$ over the important part of the resonance-capture region.

The calculated HTGR spectrum in the resonance region, given in

* See p. 67 of Ref. 10. 


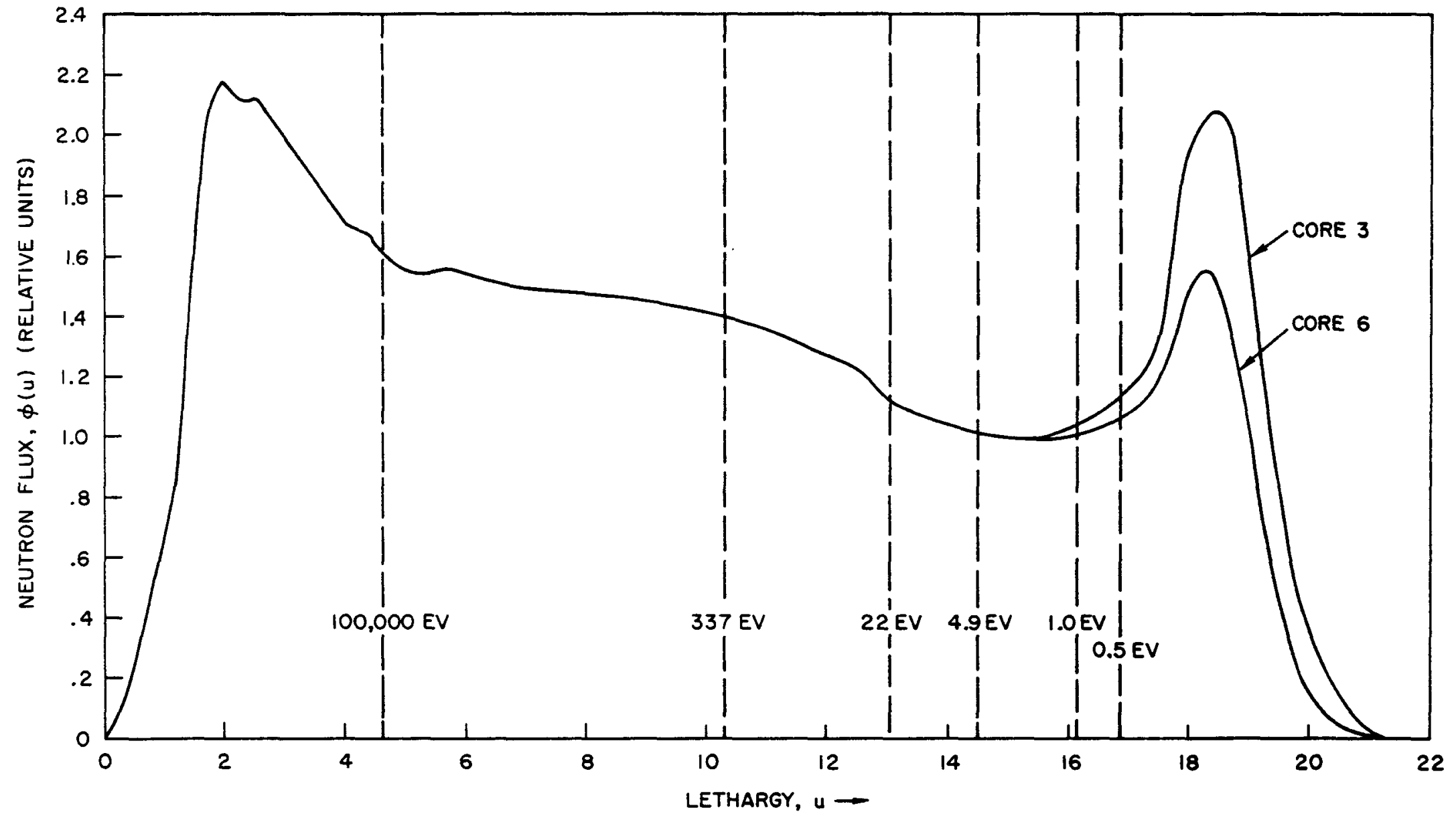

Fig. 1--Spectra at the center of cores of the critical assembly, as determined by the GAM and GATHER codes 


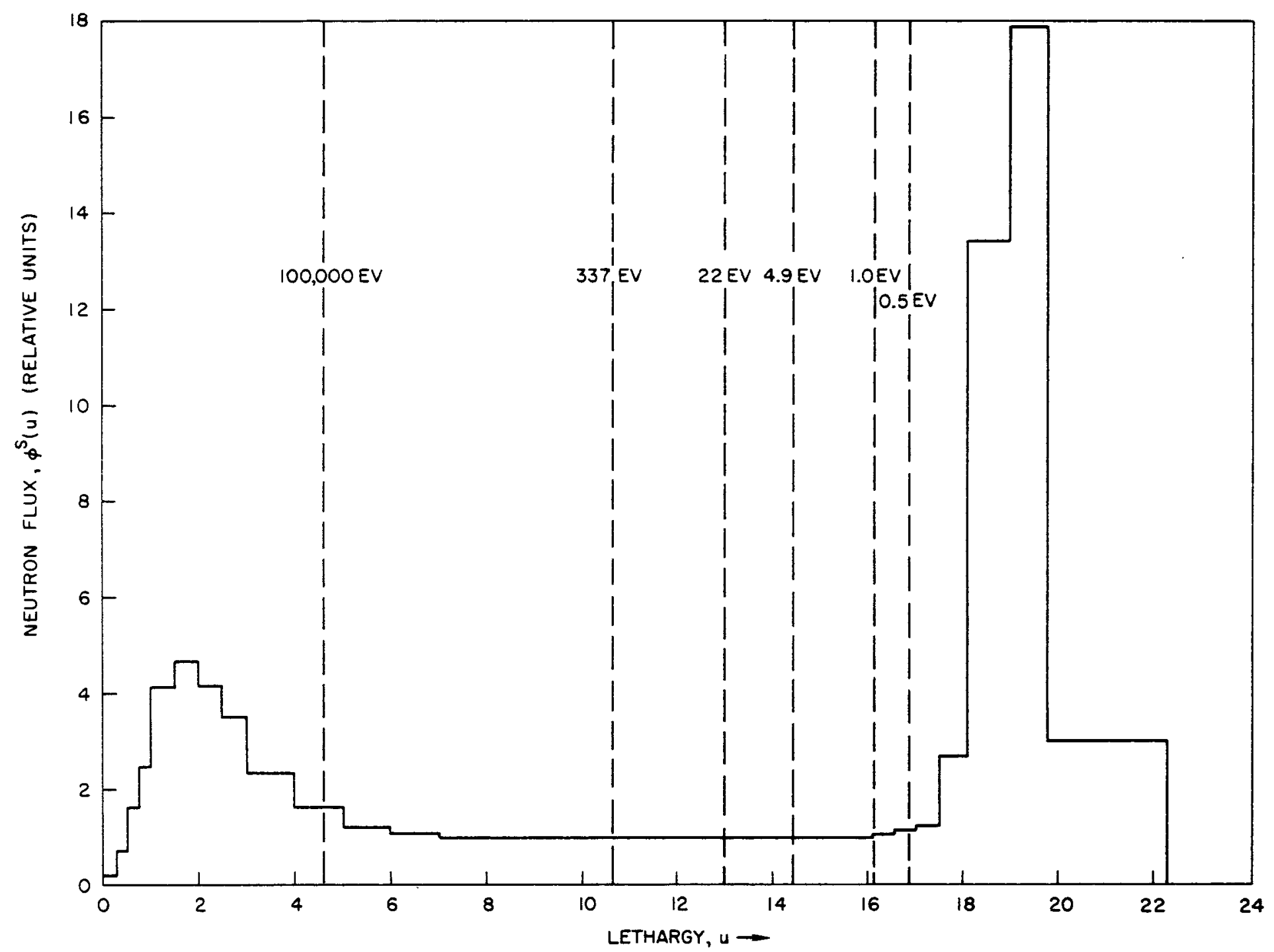

Fig. 2--Spectrum at a location $2.8 \mathrm{~cm}$ into the water reflector of the TRIGA reactor 
Fig. 1, is that for a completely homogenized reactor composition. In the actual condition of exposure, particularly in the thorium-containing elements, sharp dips occur which are very localized in energy or lethargy, caused by the local depletion of the flux by the resonance captures in thorium. These dips can be ignored in computing the Au resonance-capture rate, since it is quite improbable that any important thorium resonance occurs at the same energy as that of an important Au resonance. The same $\phi^{S}$ has also been assumed to apply to other resonance absorbers. The effect of these flux dips in the case of thorium resonance capture, where they are indeed important, is accounted for in the methods of computation of $A_{r e s}$ or $\sigma_{\text {res }}$ that have been developed. These computation methods include the effect of thorium self-shielding in the resonance region. This self-shielding also includes the resonance flux depletion inside the thoriumcontaining region. That is, $\phi^{S}$ is taken to be the nondepleted flux, in which the thorium resonance-capture rate is given by a self-shielded, effective cross section.

The cadmium cutoff, ${ }^{E_{C d}}$, has been defined in terms of the reaction rate of a l/v absorber and spectra such as that of Fig. 1. The following definition was applied to determine $\mathrm{E}_{\mathrm{Cd}}$ :

$$
\int_{0}^{\infty} \phi^{S}(E) \tau \operatorname{Cd} \sqrt{\frac{E_{0}}{E}} d E=\int_{E_{C d}}^{\infty} \phi^{S}(E) \sqrt{\frac{E_{0}}{E}} d E,
$$

where ${ }^{\top}{ }_{C d}$ is the transmission function of the 20 -mil-thick $(0.0508-\mathrm{cm})$ cadmium cover used in the se measurements.

Low-energy spectral parameters discussed in Section 2.2 have been determined for the spectra of Figs. 1 and 2 and results are given in Table 4. The resonance-capture rates of $\mathrm{Au}^{197}$ in these spectra are given in Table 5. To be expressed in units which are the same as the resonance integral, this reaction rate must be divided by a flux. The particular flux chosen, the choice of which is arbitrary, gives a normalization factor. The normalization adopted as "standard" in this work is $\bar{\phi}$, where 
Table 4

CALCULATED LOW - ENERGY SPECTRAL QUANTITIES

\begin{tabular}{l|c|c|c}
\hline Spectrum & $\begin{array}{c}E_{C d} \\
(\text { ev) }\end{array}$ & (C. R. ) $1 / \mathrm{v}$ & $T$ \\
\hline 1/E & 0.52 & & 0.44 \\
Core 3 & 0.51 & 6.95 & 0.47 \\
Core 6 & 0.51 & 5.36 & 0.47 \\
\hline
\end{tabular}

Table 5

RESONANCE REACTION RATES OF Au 197

IN CHARACTERISTIC SPECTRA

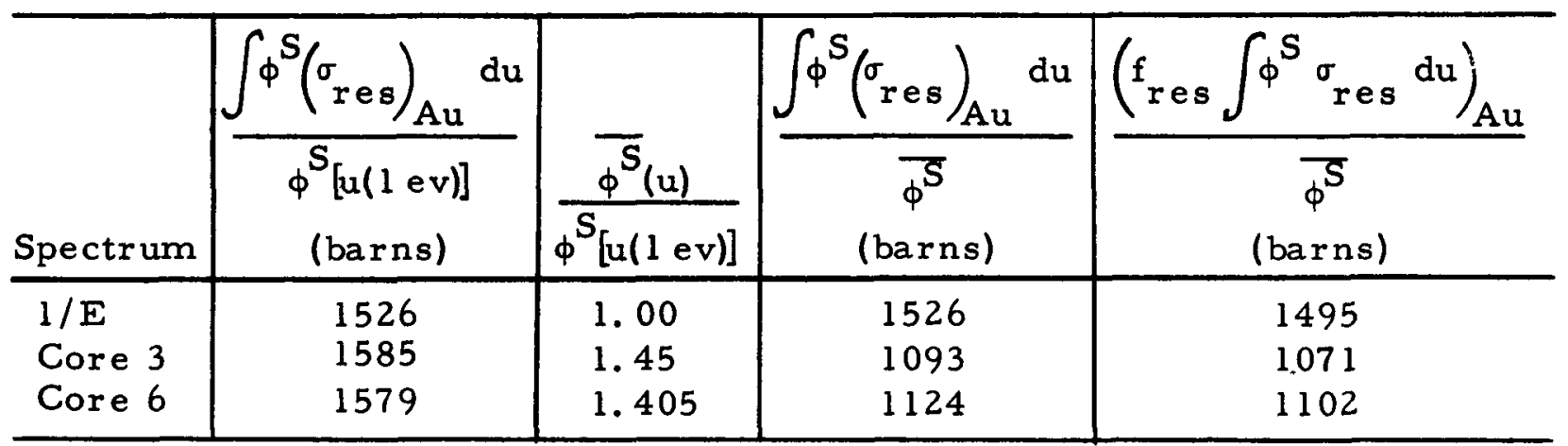

$\overline{\phi^{S}}$ is $\phi S(u)$ averaged over the lethargy interval corresponding to the energy interval between 13.7 ev and 86,500 ev:

$$
\overline{\phi^{S}}=\frac{1}{u(13.7 \mathrm{ev})-\mathrm{u}(86,500 \mathrm{ev})} \int_{u(86,500 \mathrm{ev})}^{\mathrm{u}(13.7 \mathrm{ev})} \phi^{S} \mathrm{du} .
$$

The normalization over this energy band, which includes nearly all thorium resonance captures, gives a thorium resonance reaction rate in $\phi^{S}$ which is close to the capture value for the same self-shielding in a $1 / \mathrm{E}$ spectrum. Values of the $\mathrm{Au}^{197}$ resonance reaction rate in $\phi^{\mathrm{S}}$, for this same normalization, are given in the fourth column of Table 5, the self-shielding of the $\mathrm{Au}{ }^{197}$ foil being neglected. Note that for cores 3 and 6 these values differ considerably from the $1526-\mathrm{b}$ value in a $1 / \mathrm{E}$ spectrum. This is so because $\phi^{S}$ is less at $4.91 \mathrm{ev}$, where most of the Au ${ }^{197}$ resonance captures occur, than the mean value of $\phi^{S}$ in the lethargy band extending from $13.7 \mathrm{ev}$ to $86,500 \mathrm{ev}$. 
An alternative normalization factor, namely, $1 / \phi^{S}[u(l$ ev $)]$ is implied in the analysis of Eqs. (18) through (22). This is converted to the standard normalization by dividing by $\bar{\phi} / \phi^{S}[u(1$ ev) ] for the particular spectrum. Values of this ratio for cores 3 and 6 are given in the third column of Table 5. The second column of the table gives the $\mathrm{Au}^{197}$ reaction rate under the $1 / \phi^{S},[u(1$ ev $)]$ normalization. These values for the HTGR cores are more similar to the $1 / E$ spectrum value for $\mathrm{Au}^{197}$. The values for resonance reaction rates stated in Section $V$, which have been determined by cadmium-ratio measurements, are obtained by dividing Eq. (22) by $\overline{\phi^{S}} / \phi[u(1$ ev) $]$ :

$$
\frac{\int \phi^{S}{ }_{\sigma_{r e s}^{X}}^{x} d E}{\overline{\phi^{S}}}=\frac{1}{\frac{\phi^{S}}{\phi^{S}(1 \mathrm{ev})}} \frac{1}{f_{r e s}^{X}} \frac{\left(C . R_{.}\right)_{1 / v}-\left(C . R_{.}\right)_{x}}{\left(C . R_{.}\right)_{x}-1} T \sigma_{2200^{\circ}}
$$

An additional spectral quantity useful in correlating results is a number that will semiquantitatively convert resonance captures mea sured in the reactor spectrum to the resonance integral, I, defined by Eq. (7). If all resonance captures occurred at a single energy, $E_{r e s}$, this number would be $\bar{\phi} / \phi^{S}\left(E_{r e s}\right)$. The connection between the resonance reaction rate and I would be, for the single-resonance case,

$$
\int \phi^{S}(u) \sigma_{r e s}(u) d u=\phi^{S}\left[u\left(E_{r e s}\right)\right] \int \sigma_{r e s}(u) d u=\phi^{S}\left(E_{r e s}\right) I .
$$

One thus finds I to be given approximately by

$$
\begin{aligned}
I_{\text {app }} & =\frac{1}{\phi^{S}\left(E_{r e s}\right)} \int \phi^{S} \sigma_{r e s} d u \\
& =\frac{\overline{\phi^{S}}}{\phi^{S}\left(E_{r e s}\right)} \frac{\int \phi^{S} \sigma_{r e s}}{\overline{\phi^{S}}} d u,
\end{aligned}
$$


where

$$
\frac{\overline{\phi^{S}}}{\phi^{S}\left(E_{\text {res }}\right)}=\frac{\overline{\phi^{S}}}{\phi^{S}(1 \text { ev })} \mid \frac{\phi^{S}\left(E_{r e s}\right)}{\phi^{S}(1 \text { ev })} .
$$

In practice, $E_{r e s}$ is spread over a broad energy band, but it can be considered to be given by energies of the dominant resonances. $E_{r e s}$ was estimated in this way, and Eqs. (28) and (29) then applied. Data relevant to Eqs. (28) and (29) are given in Table 6.

Table 6

DATA USED TO SEMIQUANTITATIVELY RELATE I TO REACTOR-SPECTRUM RESONANCE CAPTURE

\begin{tabular}{|c|c|c|c|c|c|c|c|c|}
\hline \multirow[b]{3}{*}{ Nuclide } & \multirow{3}{*}{$\begin{array}{c}\text { Estimated } \\
E_{\text {res }} \\
(\mathrm{ev})\end{array}$} & \multirow[b]{3}{*}{ u res } & \multicolumn{3}{|c|}{ Core 3} & \multicolumn{3}{|c|}{ Core 6} \\
\hline & & & $\bar{\phi}$ & $\phi^{S}\left(E_{r e s}\right)$ & $\bar{\phi}$ & $\bar{\phi}$ & $\phi^{S}\left(E_{r e s}\right)$ & $\overline{\phi^{S}}$ \\
\hline & & & $\overline{\phi^{\prime}(1 \mathrm{ev})}$ & $\phi \phi^{S}(1$ ev $)$ & $\phi^{\mathrm{S}}{\left(\mathrm{E}_{\text {res }}\right.}$ & $\overline{\phi^{S}(1 \mathrm{ev})}$ & $\phi^{S}(1 \mathrm{ev})$ & $\phi \phi^{S}\left(E_{\text {res }}\right)$ \\
\hline Vanadium & 6000 & 7.4 & 1.45 & 1.55 & 0.93 & 1.40 & 1.50 & 0.93 \\
\hline $\mathrm{Mn}^{55}$ & 350 & 10.2 & 1.45 & 1. 45 & 1.00 & 1.40 & 1.43 & 0.98 \\
\hline $\mathrm{Th}^{232}$ & 60 & 12.0 & 1.45 & 1.30 & 1.12 & 1.40 & 1.28 & 1.09 \\
\hline
\end{tabular}


0

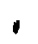

- 


\section{METHOD OF CALCULATION OF Th ${ }^{232}$ RESONANCE REACTION RATE FROM CROSS-SECTION DATA}

\section{1. STATUS OF KNOWLEDGE OF THORIUM ABSORPTION CROSS SECTIONS}

The basis of knowledge of the thorium resonance parameters is somewhat complicated, and some of the data have significant uncertainty. This uncertainty has been incorporated into the present analysis by considering two alternative sets of resonance parameters which predict resonance captures differing by about $10 \%$ from one another. A principal object of the present program of measurement and calculation is to determine which set of thorium resonance parameters is most correct.

The following background concerning knowledge of thorium resonance parameters is given for the purpose of orientation.

Recent, careful measurements ${ }^{(17)}$ of resonance parameters have been reported by Columbia University. These measurements give the values for most resonances up to about $1000 \mathrm{ev}$. However, for the four important lowest resonances below $100 \mathrm{ev}$, only $E_{0}$ was measured at Columbia, and values of $\Gamma$ quoted in Ref. 17 are actually values previously listed in BNL-325 (18)

These $\Gamma$ values for the lowest resonances are less well known than the resonances above $100 \mathrm{ev}$. They are based on older neutronspectrometer measurements made at Brookhaven ${ }^{(26)}$ and Argonne National Laboratory. Examination of the data of these measurements led J. D. Garrison ${ }^{(16)}$ to suggest that the data are not self-consistent. Selection of a part of the data would give $\Gamma_{n}$ values for the two lowest levels reduced by about $30 \%$ from the BNL values. (18) in resonance integrals for these levels, which are primarily determined by $\Gamma_{\mathrm{n}}$ rather than $\Gamma$, as $\Gamma_{\mathrm{n}}$ is much the smaller. Russian neutron- 
spectrometer measurements ${ }^{(27)}$ also have indicated lower values of $\Gamma_{n}$ for these two lowest resonances.

Consequently, the following alternative sets of data for thorium resonance parameters have been considered:

1. The set of the Columbia $\Gamma$ values above $100 \mathrm{ev}$, Columbia measurements of $E_{0}$ at all energies, and $B N L-325 \Gamma$ values below $100 \mathrm{ev}$.

2. The same data as in set $I$ except that $\Gamma_{n}$ values for the two lowest levels are reduced by the factor 0.7 .

The specific data used as set 1 have been obtained by consultation with the Neutron Cross Section Evaluation Center of Brookhaven National Laboratory. These data are listed in Table 7. Also, the revisions which lead to the data of set 2 , above, are given.

The self-explanatory terms "high" and "low" used in Table 7 and throughout the rest of this report refer to the first and second sets of resonance parameters, respectively. In both sets, the 0.030-ev value of $\Gamma_{\gamma}$ for the lowest four resonances has been assumed. This value may be inconsistent with the higher values measured at Columbia above $100 \mathrm{ev}$. The change of $\Gamma_{\gamma}$ of the lowest four levels from $0.030 \mathrm{ev}$ to $0.040 \mathrm{ev}$ would decrease the thin-limit resonance integral by only $2 \%$, so this possible inconsistency is of little practical importance.

The average values derived from the data of Table 7 are:

$$
\begin{aligned}
& \overline{\mathrm{D}}=19.8 \mathrm{ev}, \\
& \overline{\Gamma_{\gamma}}=0.041 \mathrm{ev}, \\
& \overline{\Gamma_{\mathrm{n}}^{0}}=0.00132(\mathrm{ev})^{1 / 2} .
\end{aligned}
$$

In the energy range from a few tenths of an electron volt to the thorium resonance region above $20 \mathrm{ev}$, the thorium cross section differs significantly from a $1 / \mathrm{V}$ dependence. This is primarily caused by a virtual level lying at several electron volts below zero. The reason for this virtual level, and values of resonance parameters suggested for it, have 
Table 7

RESONANCE PARAMETERS OF $T^{2} 32$

\begin{tabular}{|c|c|c|c|}
\hline $\begin{array}{c}E_{0} \\
(e v)\end{array}$ & $\begin{array}{c}\Gamma_{n} \\
\left(10^{-3} \mathrm{ev}\right)\end{array}$ & $\left(10^{-3} \Gamma_{(\mathrm{ev})^{1 / 2}}^{0}\right)$ & $\begin{array}{c}\Gamma_{\gamma} \\
\left(10^{-3} \mathrm{ev}\right)\end{array}$ \\
\hline 21.84 & $\begin{array}{l}2.4 \text { (high) } \\
1.68 \text { (low) }\end{array}$ & $\begin{array}{l}0.51 \text { (high) } \\
0.36 \text { (low) }\end{array}$ & 30 \\
\hline 23.48 & $\begin{array}{l}\text { 4. } 0 \text { (high) } \\
2.86 \text { (low) }\end{array}$ & $\begin{array}{l}0.83 \text { (high) } \\
0.59 \text { (low) }\end{array}$ & 30 \\
\hline 59.55 & 4. 6 & 0.060 & 30 \\
\hline 69.2 & 39 & 4.69 & 30 \\
\hline 113.15 & 11 & 1.04 & 42 \\
\hline 121.0 & 18.5 & 1.68 & 41 \\
\hline 128.5 & 0.10 & 0.009 & \\
\hline 129.4 & 3.1 & 0.26 & \\
\hline 146.2 & 0.10 & & \\
\hline 154.6 & 0.22 & 0.018 & \\
\hline 170.8 & 58 & 4. 45 & 48 \\
\hline 193.0 & 14 & 1.01 & 50 \\
\hline 196.8 & 0.13 & 0.009 & 0.01 \\
\hline 199.8 & 9 & 0.64 & \\
\hline 203 & & & \\
\hline 221.8 & 23 & 1.54 & 46 \\
\hline 252.3 & 24 & 1.51 & 42 \\
\hline 264 & 15 & 0.92 & \\
\hline 286.8 & 21 & 1.22 & 50 \\
\hline 306.5 & & 1. 14 & \\
\hline 330.4 & 55 & 3.02 & 53 \\
\hline 343.3 & 30 & 1.62 & \\
\hline 366.7 & 35 & 1.83 & \\
\hline 371.0 & 24 & 1.25 & \\
\hline 402.8 & 9 & 0.45 & \\
\hline 413.4 & & & \\
\hline 456.4 & & & \\
\hline 465.0 & 45 & 2.09 & \\
\hline 491.0 & 50 & & \\
\hline 513.0 & 3.5 & 0.15 & \\
\hline 531.5 & 15 & 0.65 & \\
\hline 543.0 & 1. 0 & 0.04 & \\
\hline 573.0 & 25 & 1. 04 & \\
\hline 581.0 & 1.6 & 0.06 & \\
\hline
\end{tabular}


Table 7--continued

\begin{tabular}{|c|c|c|c|}
\hline $\begin{array}{c}E_{0} \\
(\mathrm{ev}) \\
\end{array}$ & $\begin{array}{c}\Gamma_{\mathrm{n}} \\
\left(10^{-3} \mathrm{ev}\right) \\
\end{array}$ & $\begin{array}{c}\Gamma_{n}^{0} \\
\left(10^{-3}(\mathrm{ev})^{1 / 2}\right)\end{array}$ & $\begin{array}{c}\Gamma_{\gamma} \\
\left(10^{-3} \mathrm{ev}\right) \\
\end{array}$ \\
\hline 601.5 & 11 & 0.45 & \\
\hline 621.5 & 5 & 0.20 & \\
\hline 660.5 & 32 & 1.24 & \\
\hline 669.0 & 17 & 0.66 & \\
\hline 679.5 & 125 & 4.80 & \\
\hline 692.0 & 38 & 1.48 & \\
\hline 705.0 & 18 & 0.68 & \\
\hline 717.5 & 25 & 0.94 & \\
\hline 746.0 & 160 & 5.85 & \\
\hline 783.0 & 10 & 0.36 & \\
\hline 810.0 & 125 & 4.40 & \\
\hline 848.0 & 23 & 0.79 & \\
\hline 872.0 & 10 & 0.34 & \\
\hline 896.0 & 30 & 1.00 & \\
\hline 950.0 & 40 & 1. 30 & \\
\hline 970.0 & 7.5 & 0.24 & \\
\hline 990.0 & 24 & 0.76 & \\
\hline 998.0 & 70 & 2.20 & \\
\hline 1020 & & & \\
\hline 1046 & & & \\
\hline 1072 & & & \\
\hline 1085 & & & \\
\hline 1100 & & & \\
\hline 1118 & & & \\
\hline 1130 & & & \\
\hline 1.159 & & & \\
\hline 1204 & & & \\
\hline 1215 & & & \\
\hline 1238 & & & \\
\hline 1253 & & & \\
\hline 1259 & & & \\
\hline 1280 & & & \\
\hline 1303 & & & \\
\hline 1314 & & & \\
\hline 1367 & & & \\
\hline 1390 & & & \\
\hline
\end{tabular}


been given by Cooper, Garrison, and Hines. ${ }^{(28)}$ The residual $1 / v$ components from the levels lying at positive energies contribute about $0.6 \mathrm{~b}$ to the $2200-$ meter/sec cross section. A similar contribution is to be expected from distant virtual levels lying at negative energies. There remain over $6 \mathrm{~b}$ of the 2200 -meter/sec cross section unaccounted for. This remainder must be due to a nearby virtual level. Garrison, et al. , (28) determined two sets of values for this level, corresponding to $\Gamma_{\gamma}$ of $30 \times 10^{-3} \mathrm{ev}$ and $40 \times 10^{-3}$ ev. Garrison required that this cross-section fit meet the following conditions:

1. A 2200-meter/sec absorption cross section of $7.45 \mathrm{~b}$.

2. A $\sigma_{\text {total }}$ at $1 \mathrm{ev}$ of $13.4 \mathrm{~b}$, of which $11.8 \mathrm{~b}$ is potential scattering.

3. Adoption of the low values of $\Gamma_{n}$ of the $21.84-\mathrm{ev}$ and $23.48-\mathrm{ev}$ levels. The two sets of parameters so determined are as follows:

\begin{tabular}{|c|c|c|}
\hline & Set 1 & Set 2 \\
\hline $\mathrm{E}_{0}$ & $-3.5 \mathrm{ev}$ & $-4.3 \mathrm{ev}$ \\
\hline$\Gamma_{\mathbf{n}}^{0}$ & $0.636 \times 10^{-3}(\mathrm{ev})^{1 / 2}$ & $0.703 \times 10^{-3}(\mathrm{ev})^{1 / 2}$ \\
\hline$\Gamma_{\gamma}$ & $30 \times 10^{-3} \mathrm{ev}$ & $40 \times 10^{-3} \mathrm{ev}$ \\
\hline
\end{tabular}

The set having $\Gamma_{\gamma}=30 \times 10^{-3}$ has been published. ${ }^{(28)}$ The set having $\Gamma_{\gamma}=40 \times 10^{-3} \mathrm{ev}$ has been adopted in the present analysis because this value is more consistent with the best measurements of $\Gamma_{\gamma}$, namely, the Columbia University data. Unfortunately, this is slightly inconsistent with the value of $30 \times 10^{-3}$ ev used in Table 7 for the resonance region below $100 \mathrm{ev}$. The effect of the difference on the low-energy cross-section dependence is trivial.

The adoption of the $\Gamma_{\gamma}=40 \times 10^{-3}$ ev set and the reduced $\Gamma_{n}$ values of the $21.84 \mathrm{-ev}$ and $23.48 \mathrm{-ev}$ levels gives the following thorium cross section between 0 and 20 ev:

$$
\left(\sigma_{\operatorname{Th}}\right)_{\text {low }}=\frac{1}{\sqrt{E}}\left[1.59+\frac{18.28}{(E+4.3)^{2}}+\frac{9.4}{(E-21.84)^{2}}+\frac{15.1}{(E-23.48)^{2}}\right] .
$$


The second term within the brackets is due to the near virtual level, and the last two terms are due to the two lowest real resonances; the first term is the residual effect due to distant virtual and real resonances. Equation (30) and the resonance parameters of Table 7 are used to calculate $\int \phi^{S} \sigma_{\text {res }} d u$ for $T^{232}$. This calculation is discussed in Section VII.

3. 2. DETAILS OF TECHNIQUE OF COMPUTATION OF THORIUM RESONANCE CAPTURE FROM THORIUM CROSS-SECTION DATA

The best available methods have been applied to calculate thorium resonance captures under several conditions with the resonance parameters given in Table 7. This procedure yields a calculated value to be compared with the measurement obtained by the vanadium-subtraction technique. In early 1962, when this analysis was done, the most quantitative method for calculating the capture in a single resonance in a self-shielded condition was the ZUT coding ${ }^{(13)}$ of Nordheim's integral equation description of resonance captures. $(10) \dagger(11)(12)$ The ZUT code has been used as the basic quantitative computational tool. It is used to check, or "calibrate," the accuracy of the more generally useful determination of thorium resonance captures by the GAM-I slowing-down code, ${ }^{(21)}$ and also from the iterated multigroup treatment, based on GAM-I, mentioned on p. 23. The GAM-I code and the multigroup calculations treat the low-lying resonances more approximately than $Z U T$, since each resonance is treated by either the so-called I.M. (N.R.I.A.) or the N. R. approximation. *** Because of this, and because of some minor computational inaccuracies, the thorium resonancecapture rates of the GAM-I and multigroup calculations have been found to differ from those determined by ZUT by a few per cent.

*An improved version of GAM, namely, GAM-II, has since been developed (G. D. Joanou, private communication). GAM-II applies the integral-equation solution and corrects other small computational inaccuracies in GAM-I. Therefore, the checks with ZUT to be discussed are pertinent only to"the earlier GAM-I version of the code.

to See Sections 3 and 4 of Ref。 10 .

*** For a discussion of these approximations, see p. 67 of Ref。 10, and Refs. 22 and 23. 
The method of analysis adopted has therefore used both of these codes. The capture rate was first computed by GAM-I and then corrected from results of an auxiliary calculation which compares GAM and ZUT results. This comparison is described in Section 7.2. The correction obtained is also applied to final results given by the multigroup calculations.

In both GAM-I and ZUT, the effect of lattice-geometry shadowing in reducing resonance capture, which is the Dancoff-Ginsburg effect, (29) is not treated in detail for HTGR geometry and therefore must be indirectly treated in the coding instructions. These codes compute the resonancecapture rate of an isolated cylinder (or sphere or slab) embedded in moderator. The $\phi^{S}$ is determined by GAM - I or multigroup calculations. The self-shielding reduction of resonance captures is accurately calculated for this hypothetical, isolated cylinder, but not for the lattice.

The following approximation, suggested by L. Nordheim, ${ }^{(30)}$ has been used to simulate the lattice condition. A critical review ${ }^{(23)}$ of this approximation indicates that it should predict resonance-capture rates in the lattice to an accuracy of within a few per cent. An annulus in the lattice has the same capture rate as the single cylinder of the following modified diameter:

$\mathrm{d}=$ mean chord length of equivalent cylinder

$$
\begin{aligned}
& =\frac{4 V_{\text {annulus }}}{S_{\text {effective of annulus }}} \\
& =\frac{4 V_{\text {annulus }}}{S_{0}\left(l-C_{o}\right)+S_{i}\left(l-C_{i}\right)}, \\
& d=\frac{\left(d_{0}^{2}-d_{i}^{2}\right)}{d_{0}\left(l-C_{o}\right)+d_{i}\left(l-C_{i}\right)},
\end{aligned}
$$

where $d_{0}$ and $d_{i}$ are the outer and inner diameters of the annulus, and $C_{0}$ and $C_{i}$ are the outer and inner Dancoff shadowing factors. $C_{0}$ is computed 
by the method of Dancoff and Ginsburg (29) as though the lattice were composed of solid cylinders of thorium of diameter $d_{0} \cdot C_{i}$ is assumed to be equal to the transmission of the graphite cylinder in the center of the annulus for an impressed flux of isotropic neutrons at the surface of the cylinder; i.e.,

$$
C_{i}=1-\Sigma d_{i}\left[1-P\left(\Sigma d_{i}\right)\right]
$$

where $\Sigma$ is the macroscopic cross section of the graphite in the central cylinder and $P_{c}$ is the collision probability in this cylinder.

${ }^{*}$ For a definition and tabulation of $P_{c}$, see p. 17 ff of Ref. 31. 


\section{MEASURED RELATIVE ACTIVATIONS AND CADMIUM RATIOS}

\section{1. CONDITIONS OF MEASUREMENT}

The cadmium-ratio measurements, using detector foils having the characteristics given in Table 1 , were all carried out in the triflutes, or void spaces, adjacent to the central fuel tube. Cadmium-ratio measurements were so made in cores 3 and 6 , but not in the $1 / E$ spectrum.

Characteristics of the geometries of thorium in exposures of cores 3 and 6 are stated in Table 8. A more detailed description is given in the Appendix.

Table 8

GEOMETRIC CHARACTERISTICS OF REACTOR EXPOSURES OF THORIUM

\begin{tabular}{l|l|l|c}
\hline & $\begin{array}{c}\text { Small } \\
\text { Annulus }\end{array}$ & $\begin{array}{c}\text { Large } \\
\text { Annulus }\end{array}$ & $\begin{array}{c}\text { Buffer } \\
\text { Cylinder }\end{array}$ \\
\hline $\mathrm{C} /$ Th ratio & $\left\{\begin{array}{l}55.7 \underline{\mathrm{a}} \\
48.7 \underline{\mathrm{b}}\end{array}\right.$ & \} 125.8 & 46.8 \\
$\mathrm{~d}_{\mathrm{O}}$, in $\mathrm{cm}$ & 5.715 & 6.985 & 3.785 \\
$\mathrm{~d}_{\mathrm{i}}$, in $\mathrm{cm}$ & 3.810 & 4.445 &.--- \\
$\mathrm{C}_{\mathrm{o}}$ & 0.123 & 0.273 & 0.112 \\
$\mathrm{C}_{\mathrm{i}}$ & 0.248 & 0.203 &.--- \\
$\mathrm{d}_{\text {, in } \mathrm{cm}}$ & 2.30 & 3.37 & 4.07 \\
\hline
\end{tabular}

a For $26.5 \mathrm{wt}-\%$ loading.

$\underline{\mathrm{b}}_{\text {For }} 30 \mathrm{wt}-\%$ loading.

The Maxwellian spectrum was developed in a thermal column of graphite on the side of the TRIGA reactor. The exposure was made at a point separated from the reactor core by $110 \mathrm{~cm}$ of graphite. The cadmium ratio of $\mathrm{Au}^{197}$ measured in this exposure position was about 200. These 
conditions assure a neutron spectrum very nearly Maxwellian with a maximum flux occurring very near to 2200 meters/sec.

\section{2. CADMIUM RATIOS MEASURED IN TRIFLUTES}

Table 9 gives results of measurements of the cadmium ratios made in the triflutes. The cadmium ratio (C. R.) is the activation of the bare foil divided by the activation of the cadmium-covered foil.

\section{Table 9}

CADMIUM RATIOS MEASURED IN TRIFLUTES

\begin{tabular}{l|c|c|l}
\hline Nuclide & Core & $\begin{array}{c}\text { No. of } \\
\text { Measure- } \\
\text { ments }\end{array}$ & $\begin{array}{l}\text { Measured } \\
\text { Cadmium } \\
\text { Ratio }\end{array}$ \\
\hline Au19.7 & 3 & 1 & 1.19 \\
Au 197 & 6 & 3 & $1.141 \pm 0.010$ \\
Vanadium & 3 & 1 & 5.85 \\
Vanadium & 6 & 3 & $4.877 \pm 0.070$ \\
Vanadium & 6 & 1 & 4.98 \\
Mn55 & 3 & 1 & 3.25 \\
Mn55 & 6 & 3 & $2.811 \pm 0.060$ \\
Th$^{232}$ in & 3 & 1 & 1.24 \\
triflute & 3 & & \\
\hline
\end{tabular}

${ }^{a}$ Where a C. R. has been measured several times, the mean value and range of reproducibility of experimental values are given.

\section{3. ACTIVATION RATIOS MEASURED BY THE VANADIUM- SUBTRACTION METHOD}

The activation ratios $A^{S} / A^{M}$, where $A^{S}$ and $A^{M}$ are the activations in the spectra $\phi^{S}$ and $\phi M$, respectively, are listed in Tables 10 through 12. The $\mathrm{A}^{\mathrm{S}} / \mathrm{A}^{\mathrm{M}}$ ratio for an unknown whose resonance reaction rate is to be determined, together with the same ratio for the Au ${ }^{197}$ standard, is stated in each case. All such ratios are recorded on the basis that the $\phi^{S}$ and $\phi^{M}$ are normalized with respect to each other in such a way that $A_{V}^{S} / A_{V}^{M}$ is 
unity. This unity ratio, if not explicitly stated, is therefore understood to apply to the third ratio measurement for vanadium in each case.

Table 10

RELATIVE ACTIVATION MEASUREMENTS BY VANADIUMSUBTRACTION TECHNIQUE

(Foil Detectors Exposed in Core 3 Triflutes; $\mathrm{A}_{\mathrm{V}}^{\mathrm{S}} / \mathrm{A}_{\mathrm{V}}^{\mathrm{M}}=1.00$ )

\begin{tabular}{|c|c|c|c|c|}
\hline \multirow[b]{2}{*}{ Unknown } & \multirow[b]{2}{*}{ Foil Condition } & \multirow{2}{*}{$\begin{array}{l}\text { Measurement } \\
\text { Designation }\end{array}$} & \multicolumn{2}{|c|}{$A^{S} / A^{M}$} \\
\hline & & & Unknown & $\mathrm{Au}^{197}$ \\
\hline $\mathrm{Mn}^{55}$ & Bare & A- 1 & 1. 19 & 5.45 \\
\hline $\mathrm{Mn}^{55}$ & Bare & A-2 & 1. 194 & 5.496 \\
\hline $\mathrm{Mn}^{55}$ & Cadmium-covered & B- 1 & 2. 14 & 26.66 \\
\hline $\mathrm{Mn}^{55}$ & Cadmium-covered & $B-2$ & 2.201 & 27.28 \\
\hline $\mathrm{Th}^{232}$ & Bare & C- 1 & 4.49 & 5.45 \\
\hline $\mathrm{Th}^{232}$ & Bare & $C-2$ & 4.609 & 5.496 \\
\hline $\mathrm{Th}^{232}$ & Cadmium-covered & D- 1 & 21.15 & 26.66 \\
\hline $\mathrm{Th}^{232}$ & Cadmium-covered & $D-2$ & 21.67 & 27.28 \\
\hline
\end{tabular}

Table 11

RELATIVE ACTIVATION MEASUREMENTS BY

VANADIUM-SUBTRACTION TECHNIQUE

(Cadmium-covered Detector Foils Exposed in 1/E Spectrum; $A_{\mathrm{V}}^{\mathrm{S}} / \mathrm{A}_{\mathrm{V}}^{\mathrm{M}}=1.00$ )

\begin{tabular}{|c|c|c|c|}
\hline \multirow[b]{2}{*}{ Unknown } & \multirow{2}{*}{$\begin{array}{c}\text { Measurement } \\
\text { Designation }\end{array}$} & \multicolumn{2}{|c|}{$\mathrm{A}^{\mathrm{S}} / \mathrm{A}^{\mathrm{M}}$} \\
\hline & & Unknown & $\mathrm{Au}^{197}$ \\
\hline $\mathrm{Th}^{232}$ & $\left\{\begin{array}{l}E-1 \\
E-2\end{array}\right.$ & $\begin{array}{l}19.07 \\
19.05\end{array}$ & $\begin{array}{l}27.75 \\
27.68\end{array}$ \\
\hline$u^{238}$ & $\left\{\begin{array}{l}F-1 \\
F-2\end{array}\right.$ & $\begin{array}{l}170.6 \\
165.0\end{array}$ & $\begin{array}{l}27.75 \\
27.68\end{array}$ \\
\hline $\mathrm{Mn} 55$ & $\left\{\begin{array}{l}G-1 \\
G-2\end{array}\right.$ & $\begin{array}{l}1.86 \\
1.83\end{array}$ & $\begin{array}{l}27.75 \\
27.68\end{array}$ \\
\hline
\end{tabular}


Table 12

RELATIVE ACTIVATION MEASUREMENTS BY VANADIUMSUBTRACTION TECHNIQUE

$\left(\mathrm{Th}^{232}\right.$ in Self-shielded Reactor Geometry; Foil and Compact Grind Detection; $\left.A_{V}^{S} / A_{V}^{M}=1.00\right)$

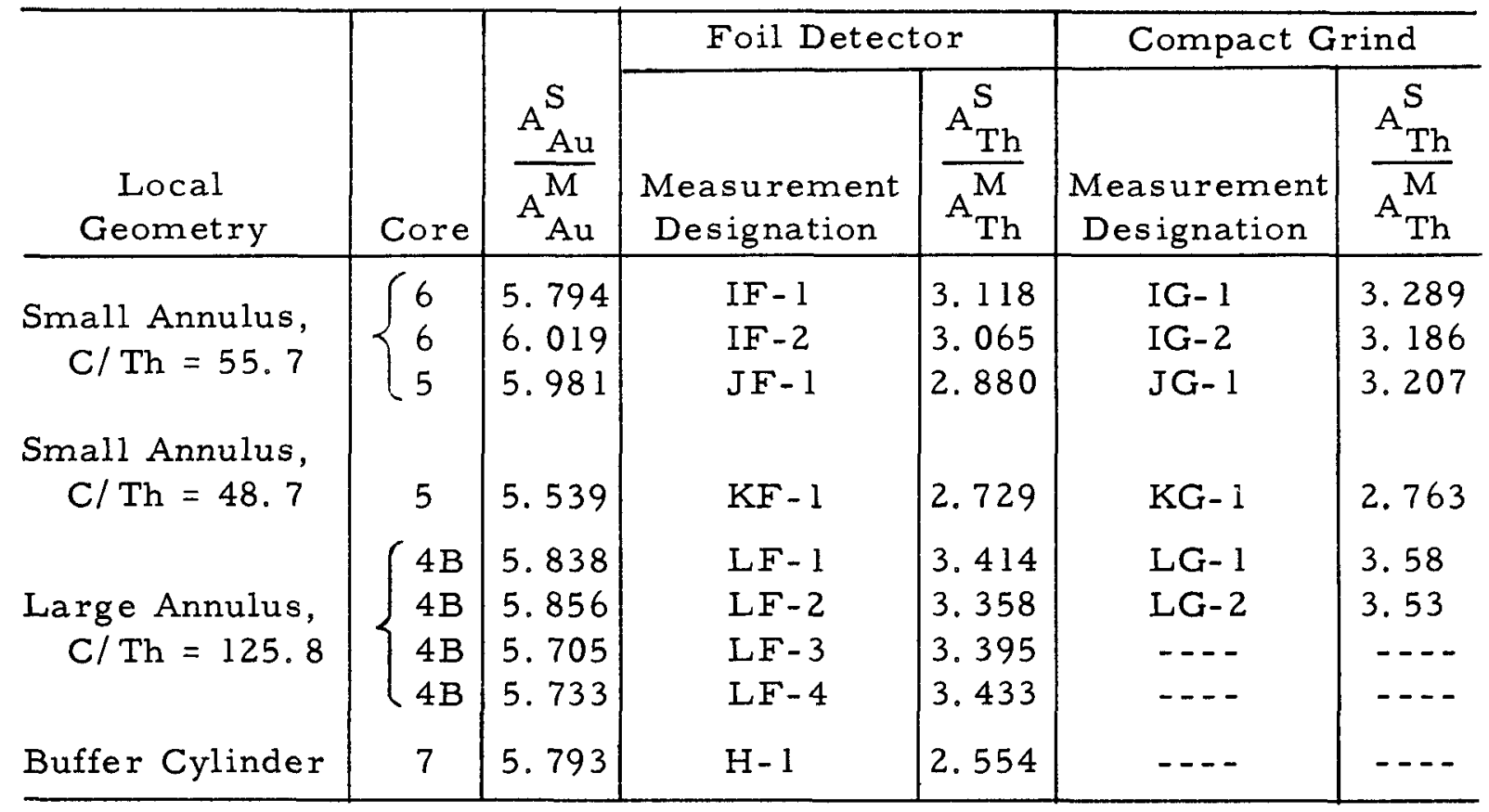

For a number of the conditions of exposure, the ratios have been measured several different times. Each of these is treated as an individual measurement. $A^{S} / A^{M}$ values for the unknown and for $A u^{197}$ are recorded in Tables 10 through 12 for each such separate measurement. Different measurements of the same exposure condition are identified by a symbol such as $A-1$, etc. The letter designates the condition of measurement and the number gives the particular measurement made in this condition. Values for the resonance-capture rates predicted by these separate measurements, labeled by the same identification numbers, are given in Section $\mathrm{V}$.

The vanadium-subtraction technique has been carried out both with and without cadmium covers on the foils. Each measurement was made with all detector foils either bare or cadmium-covered. The presence of a cadmium cover modified the $\phi^{S}$ in the low-energy region but not in the 
resonance region. The addition of such covers therefore changes the $\mathrm{A}^{\mathrm{S}} / \mathrm{A}^{\mathrm{M}}$ ratio both of the unknown and of $\mathrm{Au}^{197}$, but should lead to the same measured result for the resonance-capture rate. Exposures in the reactor annulus were made bare; those in the $1 / E$ spectrum were cadmium-covered; those in the triflutes of core 3 were made both ways. Columns of tables labeled "foil condition" tell whether the exposures were made bare or cadmium-covered.

In some of the reactor annulus geometry measurements, the "compactgrind" thorium detector technique (see Section 2. 2), as well as the thorium foil detector was applied. In each of these measurements, three foils were used, and the "compact-grind" activation constitutes a fourth observation. Where both detectors were used, separate analysis is carried out for each detector, based on the activation ratios $A_{T h}^{S} / A_{T h}^{M}$ measured for that detector and using the common values of $\mathrm{A}_{\mathrm{V}}^{\mathrm{S}} / \mathrm{A}_{\mathrm{V}}^{\mathrm{M}}$ (unity) and $\mathrm{A}_{\mathrm{Au}}^{\mathrm{S}} / \mathrm{A}_{\mathrm{Au}}^{\mathrm{M}}$.

The l/E spectrum measurement had foils of $\mathrm{U}^{238}$ and $\mathrm{Mn}$ as well as $\mathrm{Th}^{232}$, and these three were exposed simultaneously as unknowns to be measured in terms of the data for $\mathrm{Au}{ }^{197}$ and $\mathrm{V}$ which were exposed at the same time.

For the large-annulus geometry, the compacts, or annuli containing $\mathrm{Th}^{232}$, contained $\mathrm{ThO}_{2}$ grains with an average size of 237 microns. This introduced additional self-shielding associated with the grains. A correction for this additional self-shielding increases captures $6 \%$. $(32)(33)$ This increase in the value measured by the compact-grind detector has been included in Table 17, in Section VI. This corrected value can then be compared with a value calculated on the basis of no self-shielding, given in Table 21, Section VIII. The grains of compact-grind detection cases other than the large HTGR annulus were small enough that grain selfshielding was insignificant. 


\section{CADMIUM-RATIO-MEASURED RESONANCE CAPTURE RATES}

The measurements listed in Table 9 were analyzed by Eqs. (22) and (28), together with pertinent auxiliary data of Tables 1, 4, and 6. The results obtained for both $\int \phi^{S} \sigma_{\text {res }} \mathrm{du} / \overline{\phi^{S}}$ and an approximate resonance integral, I app' are given in Table 13. These data are the final results of investigations carried out in this work by the cadmium-ratio technique. As was pointed out in Section 2. 2, the results were not determined relative to $\mathrm{Au}^{197}$ but rather with the aid of computed spectral quantities and Eq. (22). It was also pointed out that the accuracy is not high, and is believed to be about $\pm 10 \%$ for the resonance integral of $\mathrm{Th}^{232}$ and $\mathrm{Mn}^{55}$, and about $\pm 50 \%$ for the resonance integral of vanadium.

Table 13

RESONANCE CAPTURES DETERMINED FROM CADMIUM-RATIO MEASUREMENTS MADE IN TRIFLUTES (Reduction of Experimental Data Given in Table 9)

\begin{tabular}{|c|c|c|c|c|c|}
\hline Nuclide & Core & $\begin{array}{c}\text { Number of } \\
\text { Measure- } \\
\text { ments }\end{array}$ & $\begin{array}{l}\sigma_{2200} \\
\text { (barns) }\end{array}$ & $\frac{\int_{\phi}^{S} \sigma_{r e s} d u}{\overline{\phi^{S}}}$ & $\begin{array}{c}\text { I app } \\
\text { (barns) }\end{array}$ \\
\hline Vanadium & 3 & 1 & 4.5 & 0.33 & 0.31 \\
\hline Vanadium & 6 & 3 & 4. 5 & 0.19 & 0.18 \\
\hline Vanadium & 6 & 1 & 4. 5 & 0.15 & 0.14 \\
\hline $\mathrm{Mn}^{55}$ & 3 & 1 & 13.2 & 7.4 & 7.4 \\
\hline $\mathrm{Mn}^{55}$ & 6 & 3 & 13.2 & 6.4 & 6.2 \\
\hline $\mathrm{Th}^{232}$ & 3 & 1 & 7.45 & 60.0 & 66.3 \\
\hline
\end{tabular}

The results of measurements of the resonance integral of vanadium of Table 13 can be written

$$
\begin{aligned}
& I_{V}=I_{\text {app }} \text { of vanadium } \\
& I_{V}=0.25 \pm 0.15 \mathrm{~b} .
\end{aligned}
$$


The indicated range of uncertainty is written conservatively large to include the possibility of an error in the value calculated for (C. R. ) $1 / v^{*}$ Evidence discussed in Section IX indicates that the higher (core 3) result for the $I_{V}$ is the more correct, and some weight has been given to this fact in selecting the $0.25-b$ average value.

This value of $I_{V}$ is determined for the mixture of nuclides occurring in the natural state, and it is measured relative to a 4 . 5-b value of the 2200-meter/sec activation cross section. This $2200-$ meter/sec value is poorly known, and this uncertainty contributes additional uncertainty to $\mathrm{I}_{\mathrm{V}}$. However, this additional uncertainty is of no concern in the analysis of measurements made by the vanadium-subtraction technique, since only the ratio of $I_{V}$ to $\sigma_{2200}$ occurs in these analyses, through the occurrence of the ratio in Eq. (14). The 2200-meter/sec cross section of vanadium does not occur in Eq. (1). That is, the result $I_{V}=0.25 \pm 0.15 \mathrm{~b}$ is a value measured relative to a 4.5-b value of the 2200-meter/sec cross section of vanadium. But results obtained by Eqs. (1) and (14) are independent of possible revision in the $2200-$ meter/sec value, and the consequent modification of $\mathrm{I}_{\mathrm{V}}$.

The value obtained for $\mathrm{I}_{\mathrm{V}}$ is consistent with the known nuclear data. The measured resonance parameters of BNL-325 and an estimate of $\Gamma_{\gamma}=0.5$, which is consistent with nuclear theory and measurements of $\Gamma_{\gamma}$ of other nuclides of about mass 55 , would predict $I_{V}$ to be $0.2 \mathrm{~b}$.

The values of $0.25 \pm 0.15 \mathrm{~b}$ for $\mathrm{I}_{\mathrm{V}}$ and $4.5 \mathrm{~b}$ for $\sigma_{2200}$ of vanadium have been applied to determine the values of $\mathrm{K}$ given in Table 14 . Other data pertinent to determining $K$ are given in Tables 4 and 6 . Equations (14), (18), (21), and (28) have been applied to these determinations. The range of uncertainty in $\mathrm{K}$ given in $\mathrm{Table} 14$ is that due to the uncertainty in $\mathrm{I}_{\mathrm{V}}$. 
Table 14

VALUES OF K FOR SPECTRA OF VANADIUM SUBTRACTION MEASUREMENTS

\begin{tabular}{l|c|c}
\hline \multirow{2}{*}{ Spectrum } & Bare & Cadmium-covered \\
\cline { 2 - 3 } & --- & $0.888 \pm 0.056$ \\
Core 3 & $0.975 \pm 0.015$ & $0.845 \pm 0.072$ \\
Core 6 & $0.967 \pm 0.017$ & -- \\
\hline
\end{tabular}


0 


\section{RESULTS OF RESONANCE-CAPTURE MEASUREMENTS BY THE}

VANADIUM-SUBTRACTION TECHNIQUE

Equation (1), the $\mathrm{Au}^{197}$ resonance-capture rates of Table 5, and the pertinent auxiliary data of Tables 1 and 14 are applied to the measurements reported in Tables 10 through 12. Results for resonance-capture rates and resonance integrals so obtained appear in Tables 15 through 17.

Table 15

RESONANCE CAPTURES DETERMINED FROM VANADIUMSUBTRACTION MEASUREMENTS IN TRIFLUTE OF CORE 3

(Reduction of Experimental Data Given in Table 10)

\begin{tabular}{|c|c|c|c|c|}
\hline Unknown & $\begin{array}{c}\text { Foil } \\
\text { Condition }\end{array}$ & $\begin{array}{l}\text { Measure- } \\
\text { ment } \\
\text { Designa- } \\
\text { tion } \\
\end{array}$ & 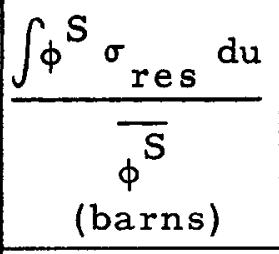 & $\begin{array}{c}\text { I app } \\
\text { (barns) }\end{array}$ \\
\hline $\begin{array}{l}\mathrm{Mn}^{55} \\
\mathrm{Mn}^{55} \\
\mathrm{Mn}^{55} \\
\mathrm{Mn}^{55}\end{array}$ & $\begin{array}{l}\text { Bare } \\
\text { Bare } \\
\text { Cadmium-covered } \\
\text { Cadmium-covered }\end{array}$ & $\begin{array}{l}A-1 \\
A-2 \\
B-1 \\
B-2\end{array}$ & $\begin{array}{l}7.4 \\
7.3 \\
7.5 \\
7.7\end{array}$ & $\begin{array}{l}7.4 \\
7.3 \\
7.5 \\
7.7\end{array}$ \\
\hline $\begin{array}{l}\operatorname{Th}^{232} \\
\operatorname{Th}^{232} \\
\operatorname{Th}^{232} \\
\operatorname{Th}^{232}\end{array}$ & $\begin{array}{l}\text { Bare } \\
\text { Bare } \\
\text { Cadmium-covered } \\
\text { Cadmium-covered }\end{array}$ & $\begin{array}{l}C-1 \\
C-2 \\
D-1 \\
D-2\end{array}$ & $\begin{array}{l}65.7 \\
65.8 \\
67.2 \\
68.5\end{array}$ & $\begin{array}{l}73.5 \\
73.5 \\
75.4 \\
76.6\end{array}$ \\
\hline
\end{tabular}

The uncertainties in $\mathrm{K}$ caused by the uncertainty in $\mathrm{I}_{\mathrm{V}}$ lead, in turn, to some uncertainties in the resonance-capture rate measured for the unknowns. The uncertainty so caused in I can be seen to be about $\pm 0.2 \mathrm{~b}$, or less than $1 \%$, for $\mathrm{Th}^{232}$ and $\mathrm{U}^{238}$. The uncertainty is about $\pm 0.6 \mathrm{~b}$, or $\pm 8 \%$, in the case of $\mathrm{Mn}^{55}$. These uncertainties are modest, and that for $\mathrm{Th}^{232}$ is quite negligible. 
Table 16

RESONANCE CAPTURES DETERMINED FROM VANADIUMSUBTRACTION MEASUREMENTS IN 1/E SPECTRUM

(Reduction of Experimental Data Given in Table 11)

\begin{tabular}{|c|c|c|c|}
\hline Unknown & $\begin{array}{c}\text { Measurement } \\
\text { Designation }\end{array}$ & $\frac{\phi_{\text {res }}^{S} d u}{\overline{\phi^{S}}}$ & $\begin{array}{c}I \\
\text { (barns) }\end{array}$ \\
\hline $\operatorname{Th}^{232}$ & $E-1$ & 78.9 & 78.9 \\
\hline$T h^{232}$ & $E-2$ & 79.0 & 79.0 \\
\hline $\mathrm{U}^{238}$ & $F-1$ & 269 & 269 \\
\hline $\mathrm{U}^{238}$ & $\mathbf{F}-2$ & 261 & 261 \\
\hline $\mathrm{Mn}^{55}$ & $G-1$ & 7.6 & 7.6 \\
\hline $\mathrm{Mn}^{55}$ & G-2 & 7. 4 & 7.4 \\
\hline
\end{tabular}

Table 17

VANADIUM-SUBTRACTION-DETERMINED RESONANCE CAPTURES IN Th232 IN SELF-SHIELDED REACTOR CONDITIONS

(Reduction of Experimental Data Given in Table 12)

\begin{tabular}{|c|c|c|c|c|c|c|}
\hline \multirow{3}{*}{$\begin{array}{c}\text { Local } \\
\text { Geometry }\end{array}$} & \multirow[b]{3}{*}{ Core } & \multicolumn{2}{|c|}{ Foil Detector } & \multicolumn{3}{|c|}{ Compact Grind } \\
\hline & & \multirow{2}{*}{$\begin{array}{l}\text { Measure- } \\
\text { ment } \\
\text { Designa- } \\
\text { ation }\end{array}$} & \multirow{2}{*}{$\frac{\phi^{S} \sigma_{\text {res }} d u}{\overline{\phi^{S}}}$} & \multirow{2}{*}{$\begin{array}{l}\text { Measure- } \\
\text { ment } \\
\text { Designa-- } \\
\text { ation }\end{array}$} & \multicolumn{2}{|c|}{$\frac{\int \phi^{S} \sigma_{\text {res }} d u}{\phi^{S}}$} \\
\hline & & & & & (a) & (b) \\
\hline Small annulus: & & & & & & \\
\hline $\mathrm{C} / \mathrm{Th}=55.7$ & 6 & IF - I & 37.0 & $\mathrm{IG}-1$ & 38.6 & 38.6 \\
\hline $\mathrm{C} / \mathrm{Th}=55.7$ & 6 & IF -2 & 35.8 & $\mathrm{IG}-2$ & 36.5 & 36.5 \\
\hline $\mathrm{C} / \mathrm{Th}=55.7$ & 5 & $\mathrm{JF}-1$ & 32.8 & $\mathrm{JG}-1$ & 37.2 & 37.2 \\
\hline $\mathrm{C} / \mathrm{Th}=48.7$ & 5 & $\mathrm{KF}-1$ & 33.4 & $\mathrm{KG}-1$ & 32.7 & 32.7 \\
\hline Large annulus: & & & & & & \\
\hline $\mathrm{C} / \mathrm{Th}=125.8$ & $4 \mathrm{~B}$ & $L F-1$ & 43.5 & $L G-1$ & 44.6 & 475 \\
\hline $\mathrm{C} / \mathrm{Th}=125.8$ & $4 \mathrm{~B}$ & $L F-2$ & 42.3 & $L G-2$ & 43.6 & 46.4 \\
\hline $\mathrm{C} / \mathrm{Th}=125.8$ & $4 \mathrm{~B}$ & LF - 3 & 44.3 & & & \\
\hline $\mathrm{C} / \mathrm{Th}=125.8$ & $4 \mathrm{~B}$ & $L F-4$ & 44. 8 & & & \\
\hline Buffer cylinder & 7 & $\mathrm{H}-1$ & 28.3 & & & \\
\hline
\end{tabular}

a Before correcting for grain self-shielding.

bAfter correcting for grain self-shielding. (32)(33) 
The vanadium-subtraction-technique determination of resonance captures therefore appears to be satisfactorily quantitative, despite the $\pm 50 \%$ uncertainty in knowledge of $\mathrm{I}_{\mathrm{V}}$.

The uncertainties in $\left(\int_{\phi}^{S} \sigma_{\text {res }} d u\right) / \bar{\phi}$ and I app for the several nuclides which arise from the uncertainty in knowledge of $\mathrm{I}_{\mathrm{V}}$ or $\mathrm{K}$ have not been stated in Tables 15 through 17. It is to be understood that one of the uncertainties in the results in these tables is $\pm 0.2 \mathrm{~b}$ in the case of $\mathrm{Th}^{232}$ and $\mathrm{U}^{238}$ and $\pm 0.6 \mathrm{~b}$ in the case of $\mathrm{Mn}^{55}$, resulting from the uncertainty in $\mathrm{I}_{\mathrm{V}}$. In the case of I of $\mathrm{Mn}^{55}$, very similar results have been obtained from measurements in the $1 / \mathrm{E}$ spectrum and the core 3 triflute spectrum. This consistency is evidence that the spectra in these cases have been calculated correctly.

The 265-b thin-limit resonance integral of $U^{238}$ measured in the $1 / E$ spectrum is close to other good measurements. The resonance parameters of $\mathrm{U}^{238}$ measured at Columbia University ${ }^{(17)}$ predict a 265 -b resonance integral. This further corroborates the claim that the spectrum developed in the reflector of TRIGA is $1 / \mathrm{E}$.

On the other hand, anomalously low values of $I_{a p p}$ for several nuclides result from the core 6 triflute measurements by the cadmium-ratio technique. This probably indicates some computational inaccuracy in the spectrum of core 6 in the thermal-energy region.

It should be noted that the $\mathrm{Th}^{232}$ exposed in the triflute has its resonancecapture rate reduced by the Dancoff-Ginsburg ${ }^{(29)}$ shadowing effect of the surrounding thorium. This shadowing has not been determined for this complicated exposure condition, but it would reduce thorium resonance captures by $10 \%$ to $20 \%$. Because of this uncertainty in shadowing, and because the vanadium-subtraction and cadmium-ratio measurements for $\mathrm{Th}^{232}$ foils in the triflute are so different, the significance of these $\mathrm{Th}^{232}$ triflute measurements is difficult to determine. 


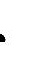




\section{QUANTITATIVE CALCULATION OF THORIUM}

\section{RESONANCE CAPTURES}

The thorium capture rate is determined from data of Table 7, Eqs. (31) and (32), and application, described in Section 3.2, of the GAM-I code and related multigroup calculations, and the ZUT code. In addition, several other small corrections must be made; these are described in the following subsections.

\section{1. SPECIAL CORRECTIONS TO CALCULATED RESONANCE- CAPTURE RATE}

Two corrections must be made in all cases, * and an additional correction for the large annulus, in order to make the calculations consistent with the conditions of measurement; these measured results are those given in Tables 15 through 17.

The resonance-capture rate is calculated on the basis of a BreitWigner single-level model of the cross section. The lower limit of the range of integration is $19.5 \mathrm{ev}$ for $\mathrm{Th}^{232}$. On the other hand, the vanadiumsubtraction technique measures a lesser rate, since Eq. (30) shows that the low-energy cross section is less than the $1 / v$ cross section which has been experimentally subtracted. This difference is

$$
\frac{1}{\phi^{S}} \int_{0}^{19.5 \mathrm{ev}}\left[\left(\sigma_{\mathrm{res}}\right)_{\mathrm{Th}}-7.45 \sqrt{\frac{0.0253}{\mathrm{E}}}\right] \frac{\mathrm{dE}}{\mathrm{E}} \text {. }
$$

\footnotetext{
The GAM-I-ZUT definition is a more usual definition of resonancecapture rate than that measured by the vanadium-subtraction technique, and the two corrections could therefore more logically be made to the measurements instead of to the calculations. If this alternate correction procedure were followed, the thorium resonance integral would be about 1.5 b larger than the values quoted in this report. However, we have chosen the expedient of correcting the calculations to bring them in accord with the definition of Eq. (3) and the vanadium-subtraction measurements of resonance reaction rate.
} 
where $\left(\sigma_{\text {res }}\right)_{\mathrm{Th}}$ is given by Eq. (30). The revision due to a change in the low-energy cross section is called the "deviation from $1 / \mathrm{v}$ effect." This correction is about $1 \mathrm{~b}$ in magnitude.

The $1 / v$ tail is experimentally subtracted throughout the resonance region in the measurements, removing

$$
\frac{1}{\phi^{S}} \int_{19.5 \mathrm{ev}}^{\infty}\left[\phi^{S}(\mathrm{E}) 7.45 \sqrt{\frac{0.0253}{\mathrm{E}}}\right] \frac{\mathrm{dE}}{\mathrm{E}} \text {, }
$$

compared with results of GAM-I-ZUT calculations. This quantity, termed the "high $1 / v$ tail" is $0.5 \mathrm{~b}$ and $0.4 \mathrm{~b}$, in a $1 / \mathrm{E}$ and any reactor spectrum, respectively.

The large annulus is embedded in a surrounding lattice of small annuli. It is calculated by GAM-I as though it were in its own environment, with d of Eq. (31) determined accordingly. The smaller-annulus neighbors exert less shadowing in the measured condition because of the difference in $\mathrm{C}_{\mathrm{O}}$ of the two lattices. From results for resonance integral as a function of $d$, it is estimated that this "environment mismatch" should increase the calculated value of $\left(\int_{\phi}^{S} \sigma_{\text {res }} \mathrm{dE}\right) / \overline{\phi^{S}}$ of the large annulus by $0.4 \mathrm{~b}$.

\section{2. COMPUTATIONAL CORRECTIONS TO GAM-I RESULT DETERMINED BY COMPARISON WITH ZUT}

The need for this comparison was stated in Section 3. 2. The comparison has been made for both the large annulus and for the small annulus having a $\mathrm{C} / \mathrm{Th}$ ratio of 55.7. These comparisons are made under the following conditions:

1. Fixed resonance parameters, having "low" values.

2. Resolved resonances.

3. $1 /$ E spectrum.

Two types of computational inaccuracies occurred in GAM-I as applied to the analysis of these measurements. The larger was that made by the application of the N.R. or I. M. (N. R. I. A. ) approximations instead of the 
integral equation solution. The second was an error caused by the roughness of interpolation applied by GAM-I to compute the surface component of the Wigner resonance integral. This interpolation is based on tables for which the surface integral had been well determined by the AdlerNordheim method, ${ }^{(34)}$ but only for rather widely spaced intervals of the geometric parameter, z. Calculations of Van Howe ${ }^{(35)}$ have shown that interpolation errors occur due to the use of these intervals, which are about $5 \%$ of the surface component of the resonance integral, or about $2 \%$ or more of the resonance integral in HTGR geometry.

These small computational errors are significant primarily for the resolved resonances, and, in fact, the comparisons to be reported show that most of the corrections occur below $100 \mathrm{ev}$ in energy. It has therefore been assumed that the correction can be adequately obtained by a comparison computation in a $1 / E$ spectrum and that the correction in all reactor spectra is adequately given by multiplying this $1 / \mathrm{E}$ spectrum correction by the factor 0.9 to obtain the correction to $\int \phi^{S} \sigma_{r e s} d u \bar{\phi}$ in the reactor spectrum. This factor is less than unity because $\phi^{S}$ at energies below $100 \mathrm{ev}$ is less than $\bar{\phi}$.

Table 18 gives a computational correction, $I_{\text {acc }}$ - I app' to the resonance integrals (in a $1 / \mathrm{E}$ spectrum) of the resolved resonance band. This computational correction is that necessary to bring $I_{\text {app }}$ determined by the Wigner resonance integral approximations (I. M. or N.R.) into agreement with $I_{\text {acc }}$ determined by the integral equation formulation. Both $I_{a p p}$ and $I_{\text {acc }}$ were determined by the ZUT code, which includes an option so that the resonance integral for each resonance can be determined in either an I. M. or N.R. manner, in addition to the integral-equation method. The particular choice of either I. M. or N.R. used to determine $I_{a p p}$ is chosen to be the same as was coded into the instructions of GAM-I as it has been used. This choice for the lowest six resonances is listed in Table 18; all other resonances were N. R. The results shown in Table 18 indicated that in HTGR geometry the I. M. approximation always overestimates the resonance 
integral, and the N. R. approximation always underestimates it. The approximation used in GAM-I is fairly satisfactory for all resonances except for the 69.2-ev resonance. For the 69.2-ev resonance, the overestimate made by the I. M. approximation, in the case of the large HTGR annulus, is 1. 51 b. Quite similar results were obtained also for calculations done on the small HTGR annulus having C/Th (carbon to thorium atomic ratio in the annulus) 55.7. For this case, the I. M. approximation overestimates the 69. 2-ev resonance integral by about 0.9 b. That is, the magnitude of the error made for the 69. 2 -ev resonance varies noticably with the geometric parameter.

Table 18

ZUT-DETERMINED COMPARISON OF ACCURATE AND APPROXIMATE THORIUM RESONANCE INTEGRAL FOR LARGE ANNULUS

\begin{tabular}{|c|c|c|c|c|}
\hline $\begin{array}{l}E_{\text {res }} \\
(\mathrm{ev})\end{array}$ & $\begin{array}{c}\text { I acc' Obtained } \\
\text { by Integral } \\
\text { Equation } \\
\text { (barns) }\end{array}$ & $\begin{array}{l}\text { Approximation } \\
\text { Used in GAM-I }\end{array}$ & $\begin{array}{l}\text { I app' Obtained } \\
\text { by GAM-I } \\
\text { Approximation } \\
\text { (barns) }\end{array}$ & $\begin{array}{c}I_{a c c}-I_{a p p} \\
\text { (barns) }\end{array}$ \\
\hline 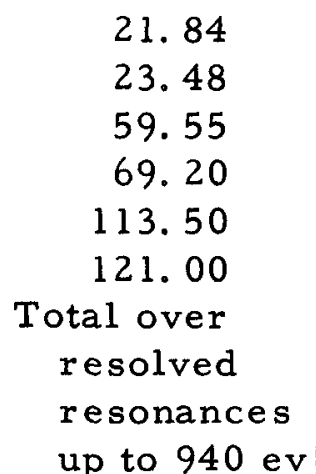 & $\begin{array}{l}7.8146 \\
9.3233 \\
3.0668 \\
4.8500 \\
1.9258 \\
2.1729 \\
43.32\end{array}$ & $\begin{array}{l}\text { I. M. } \\
\text { I. M. } \\
\text { N. R. } \\
\text { I. M. } \\
\text { N. R. } \\
\text { N. R. }\end{array}$ & $\begin{array}{l}7.8400 \\
9.4226 \\
3.0189 \\
6.3624 \\
1.8930 \\
2.1065\end{array}$ & $\begin{array}{l}-0.0254 \\
-0.0993 \\
+0.0473 \\
-1.5124 \\
+0.0328 \\
+0.0664\end{array}$ \\
\hline
\end{tabular}

The 69.2-ev resonance integral was also determined in the case of the large annulus by the N.R. approximation. This gave $4.202 \mathrm{~b}$, which is in better agreement with $I_{\text {acc }}$. However, neither the N. R. nor the I. M. approximation is very good for this resonance. This is not surprising, since it is a borderline case which does not meet the criterion well for either approximation. 
Table 19 shows the total computational error made by GAM-I, as coded in this work. This total error was determined by a different procedure, namely, by comparison of a GAM-I and ZUT calculation done for resolved resonances in a $1 / E$ spectrum. This was accomplished in the case of the GAM-I code by inserting an input parameter which made the contribution of the unresolved resonances zero. Furthermore, the contribution of the region above about $80,000 \mathrm{ev}$, which was incorporated into GAM-I by BNL- $325^{(18)}$ unshielded cross sections, was subtracted. This high-energy contribution was determined to be $0.93 \mathrm{~b}$. Table 19 also shows the second component error made by GAM-I--the interpolation error. This was actually found by subtracting the N. R. or I. M. approximation error from the total error, determined in the manner just described.

Table 19

ERRORS IN GAM -I CALCULATION FOR RESOLVED RESONANCES, 1/E SPECTR UM; "LOW" RESONANCE PARAMETERS

\begin{tabular}{c|c|c}
\hline & $\begin{array}{c}\text { Large } \\
\text { Annulus } \\
\text { (barns) }\end{array}$ & $\begin{array}{c}\text { Small } \\
\text { Annulus, } \\
\text { C/Th=55.7 } \\
\text { (barns) }\end{array}$ \\
\hline $\begin{array}{c}\text { Use of I. M. or N. R. } \\
\text { approximation } \\
\text { Interpolation } \\
\text { TOTAL }\end{array}$ & -1.24 & -0.65 \\
-0.13 & -0.42 \\
\hline
\end{tabular}

Table 19 shows that the total error made in GAM-I, which is of the order of $1 \mathrm{~b}$, or $3 \%$ of the resonance-capture reaction rate, is unimportant in the case of the small annulus having $\mathrm{C} / \mathrm{Th}=55.7$, compared with the case of the large annulus. The values of $\mathrm{C} / \mathrm{Th}$ for the large annulus and for the small annulus for which GAM-I computational inaccuracies have been evaluated are 125.8 and 55.7. It is desirable to estimate these inaccuracies also for the buffer cylinder having $\mathrm{C} / \mathrm{Th}=46.8$, and for the small 
annulus that had $\mathrm{C} / \mathrm{Th}=48.7$. It can be seen by extrapolation that the GAM - I computational inaccuracy would be quite small for these cases. It has therefore been ignored in these cases.

To recapitulate, a computational error in GAM-I as applied to this analysis has been evaluated to lead to errors in $\int \phi{ }^{S} \sigma_{\text {res }} \mathrm{du} / \phi^{S}$ for the large annulus and for the small annulus having $\mathrm{C} / \mathrm{Th}=55.7$ of $1.2 \mathrm{~b}$ and $0.2 \mathrm{~b}$, respectively. For other cases, this computational error was indicated to be small and was neglected.

\section{3. FINAL CALCULATED VALUES OF VANADIUM-SUBTRACTION- MEASURED VALUES OF THE THORIUM RESONANCE-CAPTURE REACTION RATE}

Table 20 gives the final results of calculations, including a recapitulation of the various small corrections, for $\int \phi^{S} \sigma_{\text {res }} d u / \phi^{S}$ for $\mathrm{Th}^{232}$, as measured by the vanadium subtraction technique. This rate is that defined by Eqs. (2) and (6). It is about 1.5 b less than that given by captures in the actual thorium resonances, and about $2.5 \mathrm{~b}$ less than the total capture rate above cadmium cutoff energy. Table 20 gives the calculated results, based on the thorium resonance-parameter data of Table 7, for the various geometries for which measurements have been made. 
Tabie 20

CALCULATED RESULTS FOR $\int_{\phi} S a_{\text {res }}$ du/ $\overline{\phi^{S}}$ FOR $\operatorname{Th}^{232}$ AS MEASURED BY THE VANADIUM-SUBTRACTION TECHNIQUE:

(In barns)

\begin{tabular}{|c|c|c|c|c|c|}
\hline & $\begin{array}{l}1 / \mathrm{E} \\
\text { Spectrum, } \\
\text { Tpin- } \\
\text { Limit }\end{array}$ & $\begin{array}{c}\text { Small } \\
\text { Annulus, } \\
\text { Core } 6, \\
\text { C } / \mathrm{Th}=55.7\end{array}$ & $\begin{array}{l}\text { Small } \\
\text { Annulus, } \\
\text { Core } 6 \text {, } \\
\text { C/ Th }=48.7\end{array}$ & $\begin{array}{l}\text { Litrge } \\
\text { Annulus } \\
\text { Core } 6, \\
\text { C/ Th }=125.8\end{array}$ & $\begin{array}{c}\text { Buffer } \\
\text { Cylinder, } \\
\text { Core } 7, \\
\text { C/Th=46.8 }\end{array}$ \\
\hline $\begin{array}{l}\text { Initial GAM-I calculated } \\
\int \phi^{S} \text { ores du/ } \overline{\phi S}: \\
\text { "Low" parameters } \\
\text { "High" parameters }\end{array}$ & $\begin{array}{l}81.0 \\
93.2\end{array}$ & $\begin{array}{l}35.9 \\
37.6\end{array}$ & $\begin{array}{l}33.0 \\
35.7\end{array}$ & $\begin{array}{l}43.6 \\
46.2\end{array}$ & $\begin{array}{l}30.2 \\
31.7\end{array}$ \\
\hline $\begin{array}{l}\text { Corrections: } \\
\text { Deviation from } 1 / \mathrm{v} \\
\text { High } 1 / \mathrm{v} \text { tail } \\
\text { Environment mismatch } \\
\text { Correction to GAM-I } \\
\text { TOTAL CORRECTION }\end{array}$ & $\begin{array}{l}-0.9 \\
-0.5 \\
0 \\
0 \\
-1.4\end{array}$ & $\begin{array}{l}-0.9 \\
-0.4 \\
0 \\
-0.2 \\
-1.5\end{array}$ & $\begin{array}{l}-0.9 \\
-0.4 \\
0 \\
0 \\
-1.3\end{array}$ & $\begin{array}{l}-0.9 \\
-0.4 \\
+0.4 \\
-1.2 \\
-2.1\end{array}$ & $\begin{array}{l}-0.9 \\
-0.4 \\
0 \\
0 \\
-1.3\end{array}$ \\
\hline $\begin{array}{l}\text { Corrected } \int_{\phi} S \sigma_{\text {res }} d u \sqrt{\phi^{S}} \\
\text { "Low" parameters } \\
\text { "High" parameters }\end{array}$ & $\begin{array}{l}79.6 \\
91.8\end{array}$ & $\begin{array}{l}34.4 \\
36.1\end{array}$ & $\begin{array}{l}31.7 \\
34.4\end{array}$ & $\begin{array}{l}41.5 \\
44.1\end{array}$ & $\begin{array}{l}28.9 \\
30.4\end{array}$ \\
\hline
\end{tabular}

*Obtained from total of Table 19 , multiplied by 0.9 . 
- 


\section{COM PARISON OF CALCULATED AND MEASURED RESULTS}

\section{OF THORIUM RESONANCE CAPTURES}

Table 21 presents a final comparison of the calculated results for thorium resonance captures with those measured by the vanadium-subtraction technique. The experimental results have been combined for cases where measurements of the same quantity have been repeated several times. The internal consistency of the results of Tables 15 through 17 show that the measured results should be considered to have an uncertainty, due to variation from measurement to measurement, of about $\pm 1.0 \mathrm{~b}$.

Table 21

COMPARISON OF CALCULATED AND MEASURED RESULTS FOR Th-232 RESONANCE CAPTURES

\begin{tabular}{|c|c|c|c|c|c|c|}
\hline \multirow[b]{3}{*}{$\begin{array}{c}\text { Condition } \\
\text { of } \\
\text { Measurement }\end{array}$} & \multicolumn{4}{|c|}{ Measured Resultsa } & \multicolumn{2}{|c|}{ Calculated Results } \\
\hline & \multicolumn{2}{|c|}{$\begin{array}{c}\text { Foil } \\
\text { Detector }\end{array}$} & \multicolumn{2}{|c|}{$\begin{array}{l}\text { Compact-grind } \\
\text { Detector }\end{array}$} & \multirow[b]{2}{*}{$\begin{array}{c}\text { "Low" } \\
\text { Parameters } \\
\text { (barns) }\end{array}$} & \multirow[b]{2}{*}{$\begin{array}{c}\text { "High" } \\
\text { Parameters } \\
\text { (barns) }\end{array}$} \\
\hline & $\begin{array}{c}\text { Number } \\
\text { of } \\
\text { Measure- } \\
\text { ments }\end{array}$ & $\begin{array}{c}\text { Resonance } \\
\text { Capture } \\
\text { (barns) }\end{array}$ & $\begin{array}{c}\text { Number } \\
\text { of } \\
\text { Measure- } \\
\text { ments }\end{array}$ & $\begin{array}{c}\text { Resonance } \\
\text { Capture } \\
\text { (barns) }\end{array}$ & & \\
\hline l/E spectrum, thin-limit & 2 & 79.0 & - & $\ldots$ & 79.6 & 91.8 \\
\hline Small a nnulus: & & & & & & \\
\hline In core $6 ; C / T h=55.7$ & 2 & 36.4 & 2 & 37.6 & 34.4 & 36.1 \\
\hline In core $5 ; C / T h=55.7$ & 1 & 32.8 & 1 & 37.2 & 34.4 & 36.1 \\
\hline Average with $C / T h=55.7$ & 3 & 35.2 & 3 & 37.4 & 34.4 & 36.1 \\
\hline In core $5 ; \mathrm{C} / \mathrm{Th}=48.7$ & i & 33.4 & 1 & 32.7 & 31.7 & 34.4 \\
\hline $\begin{array}{l}\text { Large grain annulus; } \\
\text { C/Th=125. } 8 \text {; compact- } \\
\text { grind-detector rrsults } \\
\text { corrected for gram seli- } \\
\text { shielding }(32)(33)\end{array}$ & 4 & 43.7 & 2 & 46.0 & 41.5 & 44.1 \\
\hline $\begin{array}{l}\text { Buffer cylinder in core } 7 \text {; } \\
\text { C/ Th }=46.8\end{array}$ & 1 & 28.3 & - & $\cdots$ & 28.9 & 30.4 \\
\hline
\end{tabular}

a All measuremonts, made by vanduum-suberction technique. 


\section{DISCUSSION OF RESULTS}

The vanadium-subtraction technique has been demonstrated to be a very useful technique for measuring resonance integrals relative to that of $\mathrm{Au}^{197}$. The experience reported here indicates that it is probably more accurate than the cadmium-ratio technique for measuring the resonance captures under Peach Bottom reactor (HTGR) conditions. For Th ${ }^{232}$, the uncertainty due to the non-1/v correction of vanadium is about $0.2 \mathrm{~b}$, and for $\mathrm{Mn}^{55}$ it is about $0.6 \mathrm{~b}$. The principal limitation to accuracy in the case of $\mathrm{Th}^{232}$ is caused by the necessity of making six activation measurements. If each activation is determined to within $1 \%$, the total error in a measured resonance reaction rate due to activation errors is probably $3 \%$ to $5 \%$. Repetition of measurements can statistically reduce this error.

Allowing for these errors, we judge the values of the thin-limit, 1/E-spectrum resonance integrals of $\mathrm{Mn}^{55}$ and $\mathrm{Th}^{232}$ determined by these vanadium-subtraction measurements to be

$$
\begin{gathered}
I_{M n} 55=7.5 \pm 0.8 \mathrm{~b}, \\
I_{T h} 232=79.0 \pm 5.0 \mathrm{~b} .
\end{gathered}
$$

The first measurement is in fair agreement with the $8.15 \pm 0.60 \mathrm{~b}$ reported by Swedish workers ${ }^{(36)}$ for the same quantity. It is less than a Knolls Atomic Power Laboratory measurement, ${ }^{(37)}$ which is $10 \mathrm{~b}$ when corrected to the same condition.

In the case of $\mathrm{Th}^{232}$, thin-limit resonance integrals ranging from 60 to $110 \mathrm{~b}$ have been previously reported. (2)(3) The measurement reported here is in good agreement with the ORNL value of $85 \pm 5 \mathrm{~b}$ above cadmium, which is equivalent to $82 \mathrm{~b}$ under conditions of this measurement. An activation measurement just reported by the British ${ }^{(39)}$ has obtained a resonance integral value of $83 \pm 6 \mathrm{~b}$ for conditions of measurement quite similar to those 
of the vanadium-subtraction method, but with the $1.5 \mathrm{~b}$ discussed in the footnote of p. 53 included. This is also in good agreement with our results.

The comparison of measured and calculated values given in Table 21 favors the "low"-resonance-parameter values. This is clearly the case for the thin-detector, 1/E-spectrum exposure, and for the cylindrical element. These two, particularly the thin-foil detector, are the geometrically simple forms that involve the least computational uncertainty in the determination of self-shielding. Furthermore, the resonance integral which is measured by the thin detector is the result most sensitive to the difference in the two alternative sets of resonance parameters.

The choice of the parameter set which best agrees with measurements for annuli is not as clear. The latest and therefore presumably the best measurements were carried out on the large annulus. One should compare the calculated results with the values measured using the foil detector, for the reason discussed in the fifth paragraph below. This would favor a choice of parameters intermediate in values between those of the "high" and "low" set. The most reasonable interpretation that can be made, before additional measurements and analyses can be carried out, is as follows:

1. The "low" set of resonance parameters is essentially correct, according to measurements made for geometrically simple conditions.

2. The computation of thorium resonance captures for the annular lattices in core 6 underestimates the capture rate by about $5 \%$. Two pieces of evidence support the second claim made above, one piece indicating the neutron spectrum assumed in the analys is is slightly incorrect. and the other indicating that self-shielding is slightly overestimated due to an overestimate of the shadowing by adjacent members of the lattice.

Cores 5 and 6 contained a driver, which gives a noticable multidimensional effect on the neutron spectrum, with a trace of this effect remaining noticable at the center of the core. The evidence for this 
effect of geometry on the spectrum is a comparison of the neutron spectrum at the center as determined by two-dimensional calculations with that determined by a one-dimensional calculation. This comparison was made for core 3, and has not yet been done for cores 5 and 6, in which the resonance reaction rates have been measured. For core 3, it was found that two-dimensional calculations predicted a somewhat harder spectrum, such that the ratio of thorium to $\mathrm{Au}{ }^{197}$ resonance captures would be increased by several per cent. This would also increase the thorium resonancecapture reaction rate by a few per cent when carried out by the methods described above.

This modification is apparently due to the spectrum-hardening effect caused by the innermost parts of the driver. This effect calculated for core 3 can be expected also to apply to cores 5 and 6 , which had a driver and had the same dimensions of regions. Core 7 , however, in which the measurement of the cylindrical element was made, contained no driver, so the spectrum computed by the one-dimensional model should apply well to that case.

The Dancoff-Ginsburg (29) calculation of the external shadowing factor, $C_{0}$, for an annulus probably somewhat overestimates this shadowing. This occurs due to the assumption that a neighboring shadowing element is completely black to resonance neutrons instead of being somewhat grey. Wagner ${ }^{(40)}$ has carried out preliminary calculations which show that an improved calculation of the external shadowing of an annulus should increase the resonance captures in the lattice by a few per cent.

It is therefore to be expected that an improved calculation of the thorium resonance-capture rate for the conditions of measurement would predict more captures. Such a modification could result in a $5 \%$ increase, to bring calculations determined from the "low" set of resonance parameters into good agreement with the measurements for the annuli.

The measured results, stated in Tables 17 and 21 , show that thorium resonance captures determined by the "compact-grind" detector are larger 
than those determined by the foil detector. Despite the scatter of measurements from case to case, a systematic difference is evident which has a probable magnitude of $5 \%$. Such an increased resonance-capture rate at $300^{\circ} \mathrm{K}$ in ceramic $\mathrm{ThO}_{2}$ is to be expected on theoretical grounds connected with the dynamics of the $\mathrm{ThO}_{2}$ crystal lattice. It is not likely that at $300^{\circ} \mathrm{K}$ the specific heat of this lattice has saturated to its high-temperature value. No measurements of the specific heat of $\mathrm{ThO}_{2}$ were found in the literature. However, the similar crystal, $\mathrm{UO}_{2}$, has been so studied. (41) In the case of $\mathrm{UO}_{2}$, the $300^{\circ} \mathrm{K}$ value of the specific heat is only about two-thirds of the saturated value, which is reached at a temperature above $900^{\circ} \mathrm{K}$.

The following summary of the influence of crystalline binding needs to be recalled ${ }^{*}$ to understand its effect on Doppler broadening.

An atom bound in a crystal lattice has a motion at low temperatures subject to less thermal excitation than a free atom. On the other hand, it is subject to zero-point vibrations, which are a quantum mechanical effect. The low-temperature specific heat increases from a small value to a saturation value at higher temperature as thermal excitation contributes more to the motion of the crystal lattice. Designate the temperature at which the specific heat saturates by $\mathrm{T}_{\mathrm{s}}$.

For temperatures $\mathrm{T}$ above $\mathrm{T}_{\mathrm{s}}$, the atoms responsible for resonance absorption can be treated as free, in that the Doppler broadening calculated on this basis is found to agree with that computed on the basis of the more correct crystal dynamics. For $\mathrm{T}<\mathrm{T}_{\mathrm{s}}$, the free-atom model predicts Doppler broadening which deviates from the more correct treatment. The effect of crystalline binding for $T<T_{S}$ can be considered to increase the effective temperature to be used in the free-atom-model determination. That is, for $\mathrm{T}<\mathrm{T}_{\mathrm{S}}$ the Doppler broadening and resonance-capture rate is increased by the effect of crystalline binding. An additional consequence of this binding effect is that the Doppler coefficient, which is the logarithmic derivative of the resonance-capture rate with respect to temperature, is

\footnotetext{
* A more complete discussion can be found in Refs. 42,43 , and 44
} 
modified. For $\mathrm{T}<\mathrm{T}_{\mathrm{s}}$, the Doppler coefficient is reduced by crystalline binding; for $\mathrm{T}>\mathrm{T}_{\mathrm{s}}$, it approaches the value determined by the free-atom model.

Most practical reactor analyses, including that applied to these measurements, $(11,12,13)$ determine Doppler broadening on the basis of the free-atom model; that is, by the assumption that the velocity distribution of resonance-absorbing atoms is Maxwellian. This can be expected to be correct for $T>T_{s}$, and to result in the errors described for $T<T_{s}$. For metallic thorium, $\mathrm{T}_{\mathrm{s}}$ is known ${ }^{(45)}$ to be less than $300^{\circ} \mathrm{K}$. Therefore, the resonance captures of the metallic-foil detector, even at $300^{\circ} \mathrm{K}$, are well described by the free-atom-model determination of this analysis. However, the thorium contained in the $\mathrm{ThO}_{2}$ crystal was the detector of the "compact-grind" method, which is indicated $(41)$ to have $\mathrm{T}_{\mathrm{s}}$ above $300^{\circ} \mathrm{K}$, but less than the operating temperature of the reactor. The present methods of calculating captures in this oxide detector can be expected to underestimate resonance captures at $300^{\circ} \mathrm{K}$. Comparison of results obtained by the metallic foil and "compact-grind" detector, given in Tables 17 and 21 , are consistent with this expectation.

Measurements made in this Laboratory on the Doppler coefficient of $\mathrm{ThO}_{2}$ dispersed in graphite ${ }^{(46)}$ provide additional evidence of a deviation of calculations at $300^{\circ} \mathrm{K}$ based on the free-atom model. These results show a measured temperature dependence of the Doppler coefficient consistent with that predicted above, if modifications due to crystalline-binding effects become important below about $500^{\circ} \mathrm{K}$.

Measurements of specific heat versus $\mathrm{T}$ for both $\mathrm{ThO}_{2}$ and $\mathrm{ThC}$ would clearly be a great help. That for $\mathrm{ThO}_{2}$ should provide additional experimental confirmation of these suggestions on resonance-capture properties measured for $\mathrm{ThO}_{2}$. ThC, which is to be used in the power HTGR, can be expected to have similar specific-heat properties as $\mathrm{ThO}_{2}$, and therefore lead to similar deviations from the present calculations of resonance capture at low temperatures. Confirmation of these expectations for ThC should be carried out. Meanwhile, these reactor physics measurements on $\mathrm{ThO}_{2}$ can be taken to provide some solid-state physics information. 
-

.

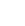




\section{CONCLUSIONS}

The significant points of these measurements and analyses for the calculation of thorium resonance captures in the HTGR can be stated as follows:

1. The "low" value set of resonance parameters of Table 7 is favored by these measurements. This "low" set is in excellent agreement with the geometrically simple measurements, particularly for the 1/E-spectrum, thin-limit case. This set predicts the following values of the resonance integral:

a. $80 \mathrm{~b}$ under the conditions of these measurements, having $\mathrm{a} \mathrm{l} / \mathrm{v}$ component which is responsible for the entire 2200-meter/sec cross section subtracted at all energies.

b. $81 \mathrm{~b}$ for the reaction rate contributed by resonances above about 19 ev.

c. $84 \mathrm{~b}$ for the epicadmium reaction rate.

These quantities all apply in a $1 / \mathrm{E}$ spectrum.

2. The methods of computing thorium resonance captures used in this analysis, which are consistent with methods contained in GAM-II, probably slightly underestimate thorium resonance captures in the HTGR in the following manner:

a. A $5 \%$ underestimate occurs at $300^{\circ} \mathrm{K}$ due to neglect of crystallinebinding effects. This error vanishes above about $600^{\circ} \mathrm{K}$, and therefore is of no importance at operating temperature.

b. The treatment of lattice shadowing for the annular-element lattice can be expected to underestimate captures by a few per cent.

3. GAM-I, with an I. M. treatment of the 69.2-ev resonance, contained additional computational inaccuracies which overestimated captures by about $3 \%$ for the large annulus, but which resulted in little error in other cases. 


\section{ACKNOW LEDGMENTS}

The pioneering work in conceiving and initiating the vanadiumsubtraction method, including the analysis in the manner of Eq. (1), was due in large part to R. G. Bardes. Outstanding help in analysis, including much of the quantitative applications of reactor codes, was provided by R. K. Lane. L. J. Todt provided valuable early computational help. Many people not included in the "Work done by" list on the title page have made important contributions to this work: Many helpful discussions and suggestions concerning resonance-escape theory and methods of analysis were provided by L. W. Nordheim. G. B. West helpfully made available and extended some of his TRIGA reactor calculations, thereby providing the $1 / \mathrm{E}$ spectrum given in Fig. 2. J. R. Brown contributed helpiul suggestions and interest throughout the analysis and report preparation. Helpful discussions were held with K. R. Van Howe, R. M. Wagner, H. B. Stewart, and G. D. Joanou. 
-

-

- 


\section{REFERENCES}

1. Drake, M. K. , and J. R. Brown, Experimental Techniques for Activation Measurement of Resonance Integrals, General Atomic, Report GA-3125, to be published.

2. Klimentov, V. B., and V. M. Gryazev, "Measurement of Neutron Resonance Absorption Integrals," J. Nuclear Energy, Vol. 9, 1959, pp. $20-27$.

3. Tattersall, R. B. , et al., "Pile Oscillator Measurements of Resonance Absorption Integrals," J. Nuclear Energy, Vol. 12-A, 1960, pp. 32-46.

4. Klein, D., et al. , "Measurements of Thermal Utilization, Resonance Escape Probability and Fast Effect in Water-moderated, Slightly Enriched Uranium and Uranium Oxide Lattices," Nuclear Sci. and Eng., Vol. 3, 1958, pp. 403-427.

5. Westcott, C. H. , The Specification of Neutron Flux and Effective Cross Sections in Reactor Calculations, Atomic Energy of Canada, Ltd. , Report AECL-352, August 15, 1956.

6. Jirlow, K. , and E. Johansson, "The Resonance Integral of Gold," J. Nuclear Energy, Vol. 11-A, 1960, pp. 101-107.

7. Macklin, R. L., and H. S. Pomerance, "Resonance Capture Integrals," Chapt. 16, Progress in Nuclear Energy, Series 1: Physics and Mathematics, R. A. Charpie, etal., ed., McGraw-Hill, New York, 1956, pp. 179-189.

8. Hardy, J., Jr., D. Klein, and G. G. Smith, "The Resonance Fission Integrals of $\mathrm{U}^{235}, \mathrm{Pu} 239$, and $\mathrm{Pu} 241, "$ Nuclear Sci. and Eng. , Vol.9, 1961, pp. 341-345.

9. Parks, D. E., J. R. Beyster, and N. F. Wikner, Thermal Neutron Spectra in Graphite, General Atomic, Report GA-2437, September 21 , 1961.

10. Nordheim, L. W., "The Theory of Resonance Absorption," Proceedings of Symposia in Applied Mathematics, Vol. XI, American Mathematical Society, Providence, Rhode Island, 1961, pp. 58-88.

11. Nordheim, L. W., A Program of Research and Calculations of Resonance Absorption, General Atomic, Report GA-2527, August 28, 1961.

12. Nordheim, L. W. , A New Calculation of Resonance Integrals, General Atomic, Report GA-2734, November 15, 1961. 
13. Kuncir, G. F., A Program for the Calculation of Resonance Integrals, General Atomic, Report GA-2525, August 28, 1961。

14. Westcott, C. H. , Effective Cross Sections for Well-moderated Thermal Reactor Spectra (3d ed.), Atomic Energy of Canada, Ltd., Report CRRP-960, September 1, 1960.

15. Gould, F. T., et al., "Long Wavelength Crystal Spectrometer and the Neutron Absorption Cross Sections of Gold and Boron," Nuclear Sci. and Eng., Vol。 8, 1960, pp.453-466.

16. Garrison, J. D., (General Atomic), private communication.

17. Argonne National Laboratorys Reports to the AEC Nuclear Cross Sections Advisory Group, September 19-21, 1960, Report Wash-1029, 1960 .

18. Hughes, D. I., and R. B. Schwartz, Neutron Cross Sections, BNL-325, 2d ed., U.S. Government Printing Office, Washington, D. C. , 1958.

19. Sampson, J. B. , Description of Peach Bottom HTGR Critical Assembly with Central Exact Region, General Atomic, Report GA-3539, October 25, 1962.

20. Brown, J. R., and M. K. Drake, Experimental Measurements on a Partial HTGR Core Mockup, General Atomic, Report GAMD-3032, June 25, 1962.

21. Joanou, G. D., and J. S. Dudek, GAM-I, A Consistent Pl Multigroup Code for the Calculation of Fast Neutron Spectra and Multigroup Constants, General Atomic, Report GA-1850, June 28, 1961 .

22. Chernick, J., and R. Vernon, "Some Refinements in the Calculation of Resonance Integrals," Nuclear Sci. and Eng. , Vol. 4, 1958, pp. 649-672.

23. Sampson, J. B., Critical Review of the Methods for Treating Geometric Effects in HTGR Annular Resonance Integral Calculations, General Atomic, Report GAMD-2660, November 29, 1961.

24. Joanou, G. D., and P. C. Kaestner, "GATHER-II, A Consistent B Code for Calculation of Thermal Neutron Spectra and Associated Multigroup Constants," Trans. Am. Nuclear Soc., Vol. 5, No. 1, 1962, Summary 14-6, p. 95.

25. Lane, R. K., (General Atomic), unpublished work.

26. Sher, R., (Neutron Cross Section Evaluation Group, Brookhaven National Laboratory), private communication.

27. Radkevich, I. A., V. V. Vladimirsky, and V. V. Sokolovsky, "The Total Neutron Cross-Sections of Pd, Os, Ir, Mo, In, I, Ta, Th, and $\mathrm{U}^{238}$ in the Resonance Region, " J. Nuclear Energy II, Vol. 5, 1957, pp. $92-107$. 
28. Cooper, G. S., J. D. Garrison, and W. A. Hines, "The Negative Energy Resonance Parameters of Th-232 and U-234," Trans. Am. Nuclear Soc., Vol. 4, No. 2, 1961, pp. 271-272.

29. Dancoff, S. M. , and M. Ginsburg, Surface Resonance Absorption in a Close-packed Lattice, Univer sity of Chicago, Report CP-2157, October 21, 1944.

30. Nordheim, L. W., (General Atomic), private communication.

31. Case, K. M., F. de Hoffmann, and G. Placzek, Introduction to the Theory of Neutron Diffusion, Vol. I, Los Alamos Scientific Laboratory, June, 1953.

32. Lane, R. K., L. W. Nordheim, and J. B. Sampson, "Resonance Absorption in Materials with Grain Structure," Trans. Am. Nuclear Soc., Vol. 5, No. 1, 1962, Summary 9-5, p. 59 (General Atomic, Report GA-2807, June, 1962).

33. Lane, R. K. , and J. B. Sampson, Calculation of Self Shielding Effect of 237 Micron Diameter $\mathrm{ThO}_{2}$ Grains on I and (1/I)(dI/dT) of an HTGR Critical Assembly Fuel Annulus, General Atomic, Report GAMD-2877 (rev.), July 6, 1962.

34. Adler, F. T., G. W. Hinman, and L. W. Nordheim, "The Quantitative Evaluation of Resonance Integrals," Proceedings of the Second United Nations International Conference on the Peaceful Uses of Atomic Energy, Vol. 16, United Nations, Geneva, 1958, p. 155.

35. Van Howe, K. R., private communication.

36. Dahlberg, R., K. Jirlow, and F. Johansson, "Measurement of Some Resonance Absorption Integrals, " J. Nuclear Energy, Vol. 14-A and B, 1961, p. 53-54.

37. Feiner, $F_{0}$, in Reactor Technology Report No. 19, December 1961, Knolls Atomic Power Laboratory, Report KAPL-2000-16, January, 1962, pp. 1. 3-1.8.

38. Johnston, F. J., J. Halperin, and R. W. Stoughton, "The Thermal Neutron Absorption Cross-Section of $\mathrm{Th} 233$ and the Resonance Integrals of $\mathrm{Th}^{232}, \mathrm{Th}^{233}$, and $\mathrm{Co}^{59}, " \mathrm{~J}$. Nuclear Energy, Vol. 11-A, 1960, pp. 95- 100 .

39. Tirén, L。 I., and J. M. Jenkins, "Resonance Shielding in ThoriumGraphite Mixtures, "United Kingdom Atomic Energy Authority, Report AEEW-R-163, March, 1962.

40. Wagner, R. M., private communication.

41. Kelley, K. K. , Contributions to the Data on Theoretical Metallurgy. X. High-Temperature Heat-Content, Heat-Capacity, and Entropy Data for Inorganic Compounds, U.S. Bureau of Mines Bulletin 476. 1949. 
42. Lamb, W. E., Jr., "Capture of Neutrons by Atoms in a Crystal," Phys. Rev., Vol. 55, 1939, pp. 190-197.

43. Nelkin, M. S., and D. E. Parks, "Effects of Chemical Binding on Nuclear Recoil," Phys. Rev., Vol. 119, 1960, pp. 1060-1068.

44. Dresner, L. , Resonance Absorption in Nuclear Reactors, Pergamon Press, Oxford, 1960, p. 33.

45. American Institute of Physics Handbook, McGraw-Hill Book Company, Inc., 1957, pp. 4-49.

46. Brown, J. R., and J. B. Sampson, Reactivity Oscillation Measurements of the Thorium Doppler Coefficient in the HTGR Critical Facility, General Atomic, Report GA-2313, July 1, 1961. 